OPEN ACCESS

Edited by:

Erica Golemis,

Fox Chase Cancer Center,

United States

Reviewed by:

Ying-Cheng Chiang,

National Taiwan University, Taiwan

Jun Peng,

Fujian University of Traditional Chinese

Medicine, China

${ }^{*}$ Correspondence:

He Zhu

zhuhe0115@126.com

Specialty section:

This article was submitted to

Cancer Molecular Targets

and Therapeutics,

a section of the journal

Frontiers in Oncology

Received: 28 September 2021

Accepted: 06 December 2021

Published: 24 December 2021

Citation:

Wang X, Du Z-w, Xu T-m, Wang X-j,

Li W, Gao J-I, Li J and Zhu H (2021)

HIF-1 $\alpha$ Is a Rational Target for

Future Ovarian Cancer Therapies.

Front. Oncol. 11:785111.

doi: 10.3389/fonc.2021.785111

\section{HIF-1 $\alpha$ Is a Rational Target for Future Ovarian Cancer Therapies}

\author{
Xin Wang ${ }^{1}$, Zhen-wu $\mathrm{Du}^{2,3}$, Tian-min Xu ${ }^{1}$, Xiao-jun Wang ${ }^{1}$, Wei $L i^{1}$, Jia-li Gao ${ }^{1}$, \\ Jing $\mathrm{Li}^{1}$ and $\mathrm{He} \mathrm{Zhu}^{1 *}$ \\ ${ }^{1}$ Department of Obstetrics and Gynaecology, The Second Hospital of Jilin University, Changchun, China, ${ }^{2}$ Department of \\ Orthopaedics, The Second Hospital of Jilin University, Changchun, China, ${ }^{3}$ Research Center, The Second Hospital of Jilin \\ University, Changchun, China
}

Ovarian cancer is the eighth most commonly diagnosed cancer among women worldwide. Even with the development of novel drugs, nearly one-half of the patients with ovarian cancer die within five years of diagnosis. These situations indicate the need for novel therapeutic agents for ovarian cancer. Increasing evidence has shown that hypoxia-inducible factor- $1 \alpha(\mathrm{HIF-1} \alpha)$ plays an important role in promoting malignant cell chemoresistance, tumour metastasis, angiogenesis, immunosuppression and intercellular interactions. The unique microenvironment, crosstalk and/or interaction between cells and other characteristics of ovarian cancer can influence therapeutic efficiency or promote the disease progression. Inhibition of the expression or activity of HIF-1 $\alpha$ can directly or indirectly enhance the therapeutic responsiveness of tumour cells. Therefore, it is reasonable to consider $\mathrm{HIF}-1 \alpha$ as a potential therapeutic target for ovarian cancer. In this paper, we summarize the latest research on the role of HIF- $1 \alpha$ and molecules which can inhibit HIF-1 $\alpha$ expression directly or indirectly in ovarian cancer, and drug clinical trials about the HIF-1 $\alpha$ inhibitors in ovarian cancer or other solid malignant tumours.

Keywords: ovarian cancer, hypoxia-inducible factors, targeted therapy, molecular target, tumour microenvironment

\section{INTRODUCTION}

Ovarian cancer is the eighth most commonly diagnosed cancer among women worldwide (1). Epithelial ovarian cancer (EOC) represents one of the deadliest cancers among women, with $47 \%$ of patients dying 5 years after EOC diagnosis (2). The standard treatment for ovarian cancer is debulking surgery combined with chemotherapy (3). Unfortunately, even when patients accept

Abbreviations: GLUT-1, glucose transporter 1; LDH-1, lactate dehydrogenase 1; MCT4, monocarboxylate transporter 4; SIK2, salt-inducible kinase 2; PI3K, phosphatidylinositol 3 kinase; AKT, protein kinase B; HK2, hexokinase 2; PFKL, phosphofructokinase, liver type; GEHT1, gastric carcinoma high expressed transcript 1; BAX, B-cell lymphoma-2 associated X; mTOR, mammalian target of rapamycin; JAK2, Janus kinase 2; STAT3, signal transducer and activator of transcription 3; CDKN2B-AS1, antisense noncoding RNA in the INK4 locus; VEGF, vascular endothelial growth factor; DSCR8, Down syndrome critical region 8; COL1A1, collagen, type I, alpha 1; PTEN, phosphatase and tensin homologue deleted on chromosome ten; ABCB5, ATP-binding cassette, sub-family B, member 5; ABCB1, ATP-binding cassette, subfamily B, member 1; MEK, mitogen-activated protein kinase kinase; ERK, extracellular regulated protein kinases; Dll4, deltalike ligand 4; ATM, ataxia telangiectasia mutated protein; TGF-1 $\beta$, transforming growth factor beta 1; PSAT1, phosphoserine aminotransferase 1; GSK3 $\beta$, glycogen synthase kinase 3 beta. 
standard treatment, recurrence occurs within 2 years in approximately $75 \%$ of patients who suffer from advanced-stage EOC (4).

The complex and rich multicellular environment in which a tumour develops is defined as the tumour microenvironment (TME) (5). In recent years, numerous studies have indicated that the TME plays a vital role in the malignant biological properties of tumours $(6,7)$, including ovarian cancer (8). With the uncontrolled growth of tumour cells and abnormalities in tumour microcirculation (9), hypoxia is an obvious feature of the TME, which is positively associated with tumour growth, angiogenesis, resistance to apoptosis and chemotherapy, and tumour metastasis (10). Hypoxia-inducible factors (HIFs) constitute a family of transcription factors that are involved in the regulation of the cellular response to hypoxic stress (11)and include three members: HIF-1 (12), HIF-2 (13), and HIF-3 (14).

HIFs, which form dimers, are composed of an oxygen-sensitive $\alpha$-subunit and constitutively expressed $\beta$ subunit $(15,16)$. There are three types of $\alpha$-subunits (HIF- $1 \alpha$, HIF- $2 \alpha$ and HIF- $3 \alpha$ ). The structures of HIF- $1 \alpha$ and HIF- $2 \alpha$ are similar but not identical, and they heterodimerize with the aryl hydrocarbon nuclear receptor translocator (also known as HIF-1 $\beta$ ) to form HIF-1 and HIF-2, respectively (17). HIFs belong to the basic-helix-hoop-helix PerArnt-Sim (bHLH-PAS) protein family and contain a bHLH domain (the bHLH domain mediates the DNA-binding activity of HIF- $\alpha$ through the specific amino acids located in this domain), followed by a PAS domain. There are two different PAS domains, named PAS-A and PSA-B. The PAS domain of HIF- $1 \alpha$ is required for the binding of hypoxia response elements (HREs) and the formation of active heterodimers. HIFs also contain an oxygen-dependent degradation domain (ODD) that is highly conserved and $\mathrm{N}$ terminal and C-terminal transactivation domains (1823) (Figure 1).

Numerous studies have found that HIF-1 participates in the process of metastasis, resistance to chemotherapy or radiotherapy and cancer stem-like cell maintenance in various types of cancers $(24,25)$ and is associated with the prognosis of gynaecological cancers (26). Thus, considering the constitutive expression of the $\beta$ subunit, targeting HIF-1 $\alpha$ may be a novel approach to treat ovarian cancer. This review summarizes recent studies on HIF- $1 \alpha$ in ovarian cancer.

\section{HIF-1 $\alpha$ IS CONSIDERED A POOR PROGNOSTIC FACTOR FOR OVARIAN CANCER}

The significance of HIF- $1 \alpha$ in solid malignant cancer varies. It is a favourable prognostic factor in renal cell cancer and early-stage squamous cell carcinomas of the oral floor $(34,35)$, but unfavourable in breast or oesophageal squamous cell carcinoma $(35,36)$. Many studies have indicated that a shorter OS is related to the positive HIF-1 $\alpha$ expression $(30-32,37,38)$. In late-stage and poorly differentiated ovarian cancer, positive HIF- $1 \alpha$ expression is related to a shorter OS time but not a shorter progression-free interval(PFI), while patients who underwent suboptimal cytoreduction and had positive HIF-1 $\alpha$ expression exhibited a shorter PFI than HIF-1 $\alpha$-negative patients (29).Only one report found no association between HIF- $1 \alpha$ and the overall survival (OS) of ovarian cancer (27). In summary, the majority of studies have indicated that HIF- $1 \alpha$ is a good predictor of a poor prognosis in ovarian cancer (Table 1).

HIF-1 $\alpha$ expression may be associated with the response to chemotherapy. Alabiad et al. reported a good response to chemotherapy in patients with low HIF-1 $\alpha$ expression (33). In contrast, researchers found that HIF-1 $\alpha$-expressing patients were more sensitive to paclitaxel/carboplatin combination chemotherapy (28), and Birner noted that HIF-1 $\alpha$ does not influence the response to platinum-based chemotherapy (27). Considering the large number of cell experiments proving that HIF-1 $\alpha$ contributes to the chemoresistance of ovarian cancer (discussed later) and the small number of samples in the studies mentioned previously, we need to further investigate the relationship between HIF-1 $\alpha$ expression and chemotherapy sensitivity (Table 1).

\section{HIF-1 $\alpha$ PROMOTES OVARIAN CANCER PROGRESSION THROUGH SEVERAL BIOLOGICAL PROCESSES}

\section{HIF-1 $\alpha$ Can Inhibit the Function of p53}

As an important tumour suppressor, p53 plays an important role in modulating drug sensitivity (39-41).After mimicking hypoxic

HIF-1

HIF-1 $\alpha$

\begin{tabular}{|l|l|l|l|l|l|l|l|}
\hline bHLH & A & PAS & B & & ODD & N-TAD & \\
C-TAD \\
\hline
\end{tabular}

HIF- $1 \beta$

\begin{tabular}{|c|c|c|c|c|}
\hline bHLH & $\mathrm{A}$ & PAS & B & $\mathrm{TAD}$ \\
\hline
\end{tabular}

FIGURE 1 | The schematic structure of HIF-1 protein. 
TABLE 1 | The association between HIF-1 $\alpha$ expression and clinical characteristics.

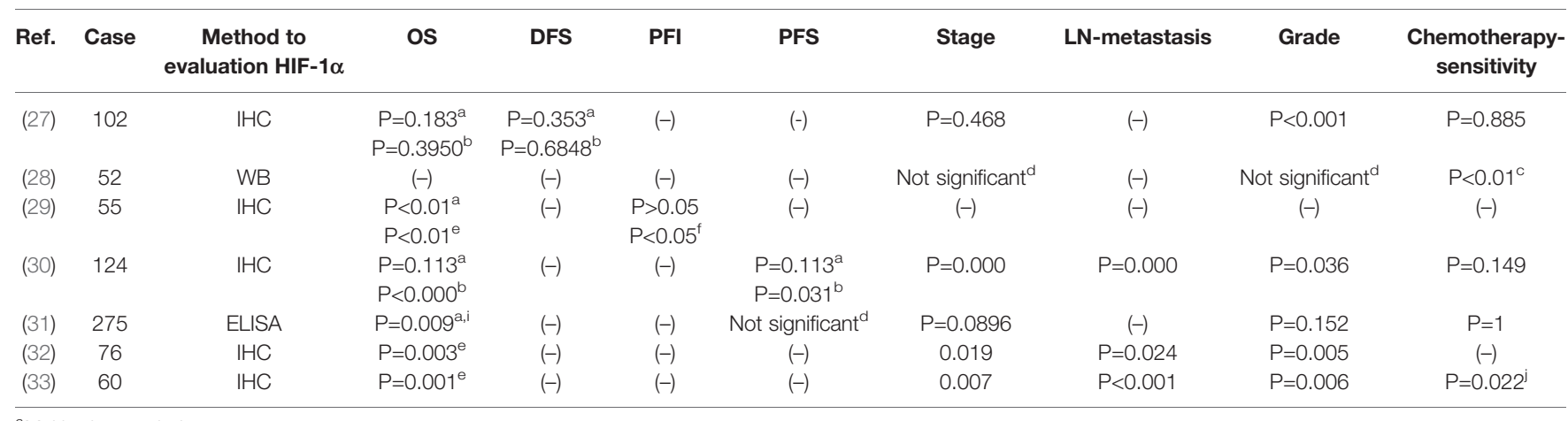

aMultivariate analysis;

${ }^{b}$ univariate analysis;

chigher HIF-1 $\alpha$ expression indicates better chemotherapy sensitivity;

${ }^{d} p$-value not shown;

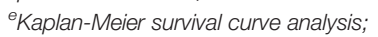

${ }^{f}$ positive HIF-1 $\alpha$ expression indicated shorter PFI in patients undergoing suboptimal cytoreduction;

gall patients were stage III/IV;

' stage I was excluded;

${ }^{i}$ cut-off value of HIF-1 $\alpha$ was $80 \mathrm{pg} / \mathrm{mg}$;

${ }^{j}$ low HIF-1 $\alpha$ expression was positively associated with a good response to chemotherapy.

stress, the p53 protein, which is supposed to be induced by doxorubicin or cisplatin, was downregulated so that apoptosis of lung and colon cancer cells mediated through $\mathrm{p} 53$ protein was diminished (42). Cisplatin can kill ovarian cancer cells through the p53-dependent apoptotic pathway $(43,44)$. Basmina et al. found that HIF- $1 \alpha$ protein binding to $\mathrm{p} 53$ protein, so that the transcriptional function of $\mathrm{p} 53$ decreased, and thus the expression of BAX downregulated, thereby affecting the apoptosis process mediated by p53 (45). Scientists have already discovered that the ODD region of the HIF- $1 \alpha$ protein can directly bind to the DNAbinding region of the p53 protein and may abolish the function of $\mathrm{p} 53$, thus hampering gene transactivation in nonmalignant cells (46).However, the accurate binding mechanism between the p53 protein and HIF-1 $\alpha$ protein in ovarian cancer is still not clear (Figure 2).

\section{HIF-1 $\alpha$ Promotes the Expression of IL-6}

Interleukin-6 (IL-6) is a multifunctional cytokine that participates in the progression of many kinds of malignant tumours (47). IL-6 is highly expressed in the serum and ascites of patients with ovarian cancer, and its upregulation is significantly associated with the poor prognosis (48-50). In colon tumour cells, HIF- $1 \alpha$ can regulate IL-6 expression via miR-338-5p (51).However, under hypoxic stress, the HIF-1 complex can promote the transcription and expression of neuronal pentraxin II (NPTX2). IL-6 expression is upregulated by NPTX2 overexpression, and the JAK2/STAT3 axis is activated via overexpression of IL- 6 to promote the proliferation, invasion and migration of EOC cells (52). In addition, IL-6 can induce nuclear translocation and elevate the transcriptional activity of HIF-1 $\alpha$ via STAT3 signalling to enhance the chemoresistance against cisplatin of ovarian cancer cells (53). It seems that there is a positive feedback loop between HIF-1 and IL- 6 that is mediated by JAK/STATA3 signalling (Figure 2).

\section{LncRNAs Promote the Progression of Ovarian Cancer via HIF-1 $\alpha$}

Long noncoding RNAs play variable roles in malignant tumours. HIF- $1 \alpha$ can regulate the expression of these noncoding RNAs, and noncoding RNAs can interact with mRNA-HIF-1 $\alpha$ to regulate the expression of HIF- $1 \alpha$ protein and then induce the progression of many types of tumours, including breast cancer (54) and ovarian cancer $(55,56)$.

The lncRNA CDKN2B-AS1 is overexpressed in ovarian cancer and can silence miR-411-3p, release HIF- $1 \alpha$ mRNA, whose translation production plays a critical role in the transcription of VEGF and $\mathrm{p} 38$, and then promote the migration and invasion of cancer cells (55). LncRNA DSCR8 is upregulated in ovarian cancer tissue and promoted tumour growth. HIF- $1 \alpha$ promote the expression of DSCR8, which can sponge miR-98-5p, so that stopping miR-98-5p targeting to the 3'-UTR of STAT3 and then promoting ovarian cancer progression by stimulating the STAT3/HIF- $1 \alpha$ pathway, which in turn upregulates DSCR8, creating a positive feedback loop to promote the progression of ovarian cancer (56) (Figure 2).

\section{HIF-1 $\alpha$ Can Stimulate the AKT/mTOR Pathway}

$\mathrm{AKT} / \mathrm{mTOR}$ pathway plays a vital role in the progression of ovarian cancer (57). Knockdown the HIF-1 $\alpha$ expression via siRNA in A2780 and SKOV3 cells significantly downregulated the phosphorylation of AKT/mTOR (58).Besides, AKT pathway regulates the expression of HIF- $1 \alpha(59,60)$ and Herpesvirus entry mediator(HVEM) is overexpressed in ovarian cancer (61). A hypoxic environment upregulates HVEM expression and enhances the phosphorylation of AKT/mTOR, thus inducing the expression of HIF-1 $\alpha$, which can promote the cell proliferation (62). It is speculated that the HEVM/ AKT/mTOR/HIF- $1 \alpha$ axis and HIF-1 $\alpha /$ AKT/mTOR axis may construct a feedback loop to promote ovarian cancer progression, which needs further investigation (Figure 2). 


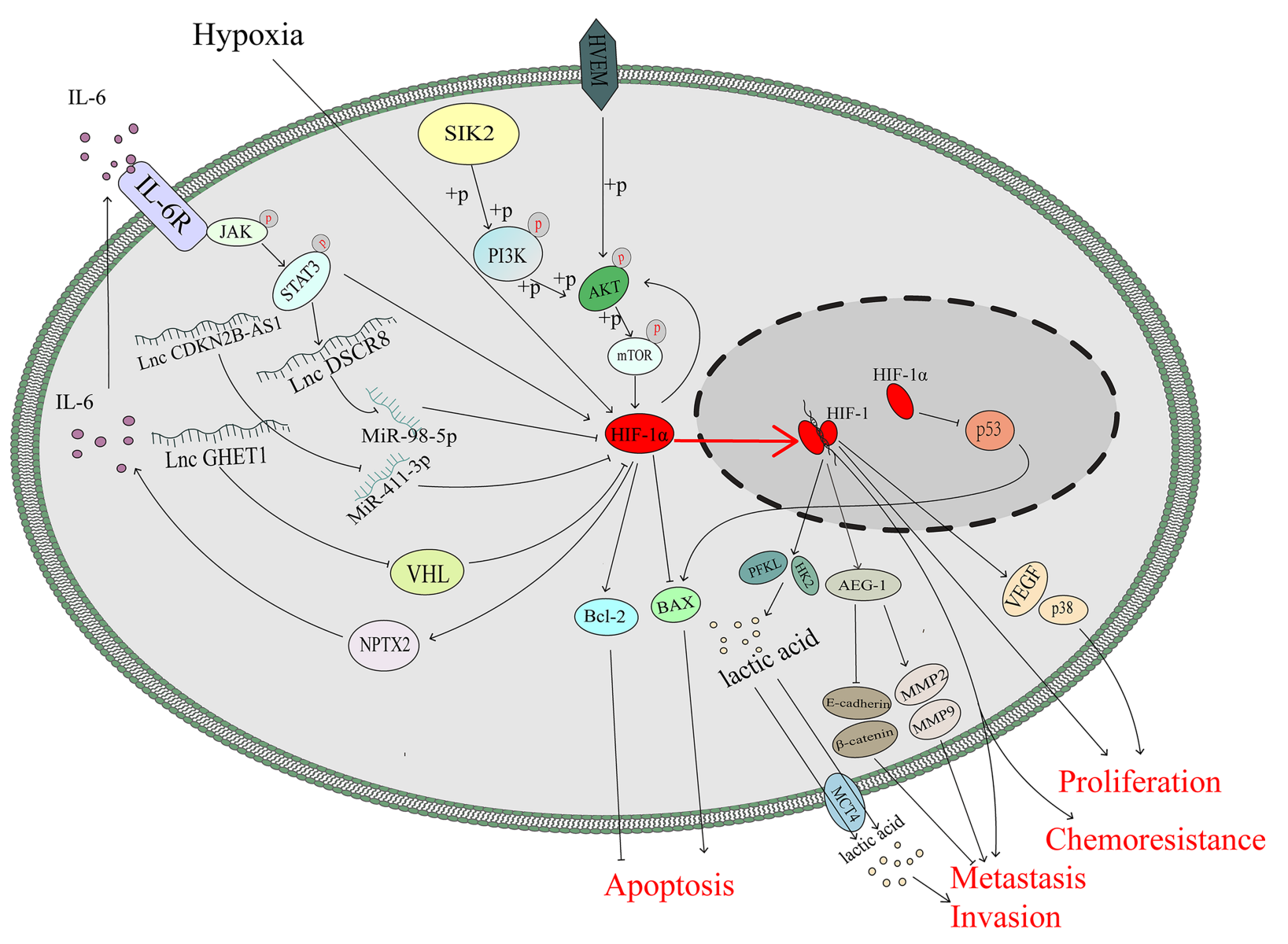

FIGURE 2 | HIF-1 $\alpha$ promotes ovarian cancer progression not only through several classical pathway but also through the function of p53 and changes in metabolism.

\section{HIF-1 $\alpha$ Promotes the Glycolysis Pathway in Ovarian Cancer}

Metabolites of the glycolysis pathway are abnormally activated in malignant tumours even under normoxia (called the Warburg effect) and promote the progression of cancers (63), including gallbladder cancer (64), pancreatic cancer (65), cervical cancer (66) and ovarian cancer (67). HIF-1 $\alpha$, as a transcription factor, can regulate metabolism-associated genes, which contribute to Warburg effect $(68,69)$. SIK2 is associated with poor outcomes in ovarian cancer, and previous studies have demonstrated that SIK2 induces ovarian cancer progression by activating the PI3K/ AKT pathway $(70,71)$. SIK2 upregulates the expression level of HIF-1 $\alpha$, which enhances the transcription of glycolysisassociated genes (HK2 and PFKL), inducing the metastasis and invasion of ovarian cancer (72). As the major rate-limiting enzymes in the glycolysis pathway, HK2 and PFKL overexpression promotes Warburg effect, which could assist the uncontrolled proliferation of cancer cells (73-75). The expression level of the long noncoding RNA (lncRNA) GEHT1 is enhanced in ovarian cancer tissue compared with normal tissue and is associated with poor prognosis. LncGEHT1 can interact with von Hippel-Lindau (VHL) to block the degradation of HIF-1 $\alpha$, thus modulating lactate production and influencing the growth of ovarian cancer (76) (Figure 2).

\section{CROSSTALK BETWEEN MALIGNANT TUMOURS AND NONMALIGNANT TUMOUR CELLS MEDIATED VIA HIF- $1 \alpha$ ACCELERATES THE PROGRESSION OF OVARIAN CANCER}

\section{Mesothelial Cells}

Mesothelial cells are among the main cellular components compromising the peritoneal cavity and omentum, which are the most common metastatic sites of advanced ovarian cancer. Mesothelial cells have been proven to play a critical role in contributing to ovarian cancer metastasis (77). A collagenremodelling gene signature containing COL1A1 and LOX is associated with the progression of ovarian cancer and unfavourable patient survival (78). Lysyl oxidase (LOX) has been proven to act as a tumour promoter (79) and regulate by HIF-1 $\alpha$ in ovarian cancer (80). Under hypoxic stress, HIF-1 could promote the 
expression of COL1A1 in the mesothelial cells and the expression of LOX in both the mesothelial and cancer cells, which remodels collagen to accelerate the invasion of ovarian cancer (81) (Figure 3).

\section{Immune Cells}

The tumour immune microenvironment contains immune cells that play considerable roles in the processes of tumour promotion and suppression (82). Studies have demonstrated that different types of immune cells infiltrating the tumour can indicate different prognoses in patients, and M2 macrophages have been significantly associated with worse outcomes for patients with ovarian cancer $(83,84)$. In the hypoxic microenvironment, ovarian cancer cells can recruit macrophages and induce their M2 transformation. Transformed macrophages likely promote the expression of miR-233 via an HIF-1 $\alpha$-dependent pathway, and miR-233 is then secreted by exosomes, which can be internalized by ovarian cancer cells. Drug resistance is promoted via exosomalderived miR-233, which activates the PI3K/AKT pathway by suppressing the expression of PTEN (85). Cancer stem-like cells (CSCs) constitute a group of special cells that have self-renewal ability and are associated with chemoresistance (86). Cytokineinduced killer cells (CIKs) were recognized in the 1990s, and investigations demonstrated that CIKs may serve in a novel treatment of cancers, including ovarian cancer $(87,88)$. Lymphocyte function-associated antigen-1 (LFA-1) is located on the membrane of CIKs and can specifically recognize intercellular adhesion molecule-1 (ICAM-1), which is highly expressed in tumour cells, thereby mediating tumour cell death (89-91), which means that the downregulation of ICAM-1 may contribute to cancer cell protection against the killing effect. In spheroid cells, which are mainly constructed by CSCs, HIF- $1 \alpha$ downregulates ICAM-1, shielding CSCs from the effect of cellular lysis mediated by CIK cells (92), and contributes to the progression of ovarian cancer (Figure 3).

\section{Adipocytes}

Obesity has been proven to be associated with a poor prognosis in ovarian cancer $(93,94)$. Studies have demonstrated that adipocytes promote ovarian cancer progression $(95,96)$. If metastasis was a random event in ovarian cancer, then the organs in the peritoneal cavity would be equally affected by focal metastasis. However, the most common distant metastasis site is the omentum, which is primarily composed of adipocytes (97). Adipocytes secrete monocyte chemotactic protein-1 (MCP-1) to bind C-C motif chemokine receptor 2 (CCR-2) on ovarian cancer cells to activate the $\mathrm{PI} 3 \mathrm{~K} / \mathrm{AKT} / \mathrm{mTOR}$ pathway, thereby increasing the expression of HIF-1 $\alpha$, which contributes to ovarian cancer metastasis (98). During the process of adipocyte differentiation, autotaxin (ATX) is released from adipocytes and promotes the synthesis of lysophosphatidic acid (LPA) (99), which is present at a high concentration in the ascites of patients with ovarian cancer (100). Early in 2006, research showed that the PI3K/Akt/mTOR pathway may be required for LPA-induced activation of HIF-1 $\alpha$ (101). Activation of the PI3K/AKT/mTOR/HIF- $1 \alpha$ axis promoted the expression of Twist, a transcription factor that increases discoidin domain receptor 2 (DDR2), which is activated by

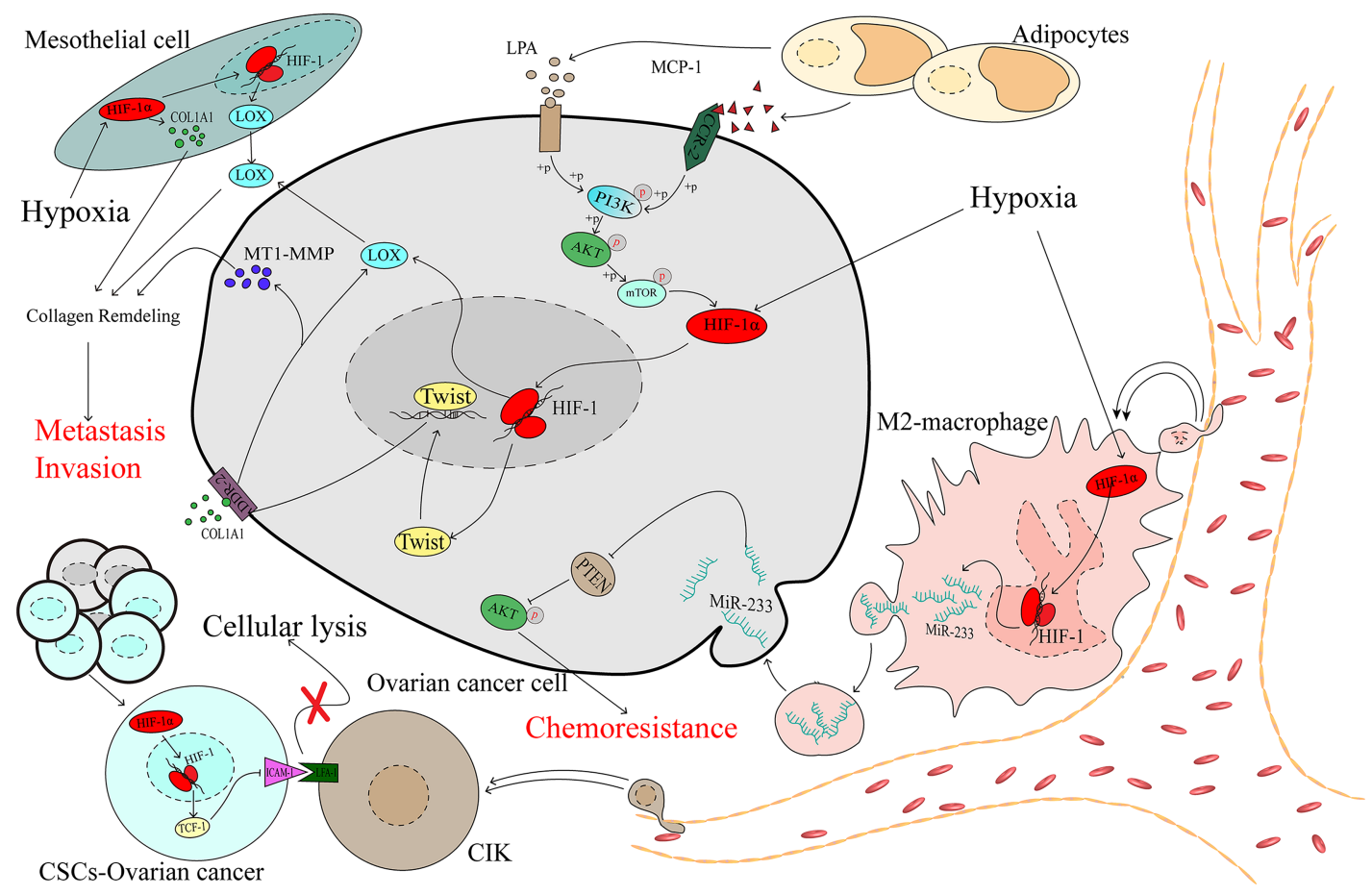

FIGURE 3 | The complex microenvironment accelerates the development of ovarian cancer as mediated by HIF-1 $\alpha$. 
collagen I (102), and then upregulates the expression of membrane type 1-matrix metallopeptidase 14 (MT1-MMP) and LOX, which is an essential factor in the invasion of ovarian cancer (103, 104) (Figure 3).

\section{MOLECULES SUPPRESSED OVARIAN CANCER PROGRESSION BY DIRECTLY OR INDIRECTLY DOWNREGULATING HIF-1 $\alpha$}

\section{Natural Compounds Extracted From Plants and Their Derivatives}

Ginsenoside 20(S)-Rg3 is an antitumoural compound extracted from Panax ginseng which is a traditional Chinese herb (105). Ginsenoside 20(S)-Rg3 can facilitate HIF-1 $\alpha$ degradation via the activation of the PHD1-VHL-ubiquitin/proteasome pathway, downregulate the expression of E-cadherin, and block the epithelial-mesenchymal transition of ovarian cancer cells in vitro and in vivo (106). Ginsenoside 20(S)-Rg3, could upregulate the expression of miR-519a-5p, which could bind to the 3'-UTR of HIF-1 $\alpha$ mRNA, then directly downregulated the expression of HIF- $1 \alpha$ (107). Considering that the Warburg effect plays a large role in promoting cancer progression (63), the inhibition of HIF- $1 \alpha$ mediated by miR-519a-5p suppressed the expression of $\mathrm{HK} 2$, which plays an important role in the Warburg effect, and this pathway may explain, at least partly, the reason why ginsenoside $20($ S)-Rg3 shows antitumoural activity ability in ovarian cancer (107) (Figure 4).

Topotecan (TPT) is a derivative of camptothecin which originates from the Camptotheca acuminata (108) and is used in the second-line treatment of ovarian cancer. A clinical trial demonstrated that TPT can downregulate HIF-1 $\alpha$ in solid advanced tumours (109). In human glioma cells, TPT can downregulate HIF- $1 \alpha$ in a topo-1-dependent manner (110). U251-HRE xenografts were treated with a low dose of daily TPT combined with bevacizumab; tumour growth was suppressed significantly, and the DAN-damage level of the two-agent treatment group was similar to that of the TPTtreatment group which indicates that the suppression of HIF$1 \alpha$ protein may contribute to the growth suppression (111). In ovarian cancer, TPT promotes mRNA-HIF-1 $\alpha$ :Topo I complex formation and then hinders the translation of the HIF- $1 \alpha$ protein (45). Because the p53 transcriptional function is eliminated when p53 binds with HIF-1 $\alpha$, the deletion of HIF$1 \alpha$ mediated by TPT can restore the function of $\mathrm{p} 53$, downregulate the expression of $\mathrm{ABCB} 5$ and $\mathrm{ABCB} 1$, modulate

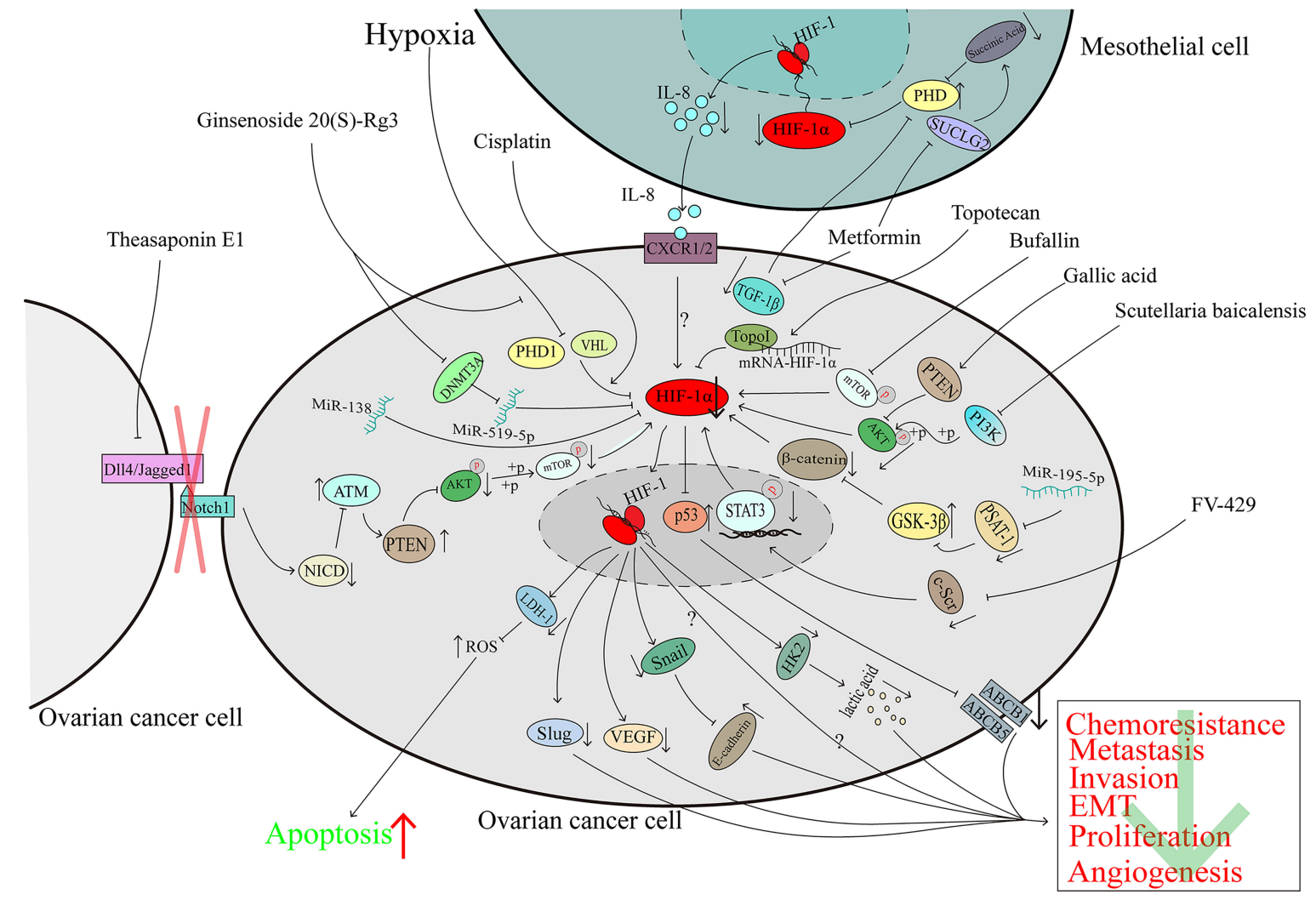

FIGURE 4 | The downregulation of HIF-1 $\alpha$ can inhibit ovarian cancer progression. The character "?" indicates that the researchers did not elaborate on the precise mechanism in their reported study. 
the cisplatin and paclitaxel resistance of ovarian cancer and promote apoptosis (45) (Figure 4).

For many years, phenolic compounds extracted from plants have been shown to play a critical role in the fight against cancer (112). In 2020, research showed that polyphenol extracts of Carya cathayensis can inhibit the proliferation of ovarian cancer and suppress VEGF expression via the inhibition of HIF-1 $\alpha$ (113). However, early in 2016, gallic acid, a main polyphenolic compound of C. cathayensis, was shown to upregulate PTEN expression and suppress the phosphorylation of AKT, which led to the downregulation of HIF-1 $\alpha$ and VEGF to hamper angiogenesis in ovarian cancer (114) (Figure 4).

The total extract of Scutellaria baicalensis inhibits the expression and enhances the degradation of HIF-1 $\alpha$ via the inactivation of the PI3K/AKT and MEK/ERK pathways and the promotion of the proteasome and lysosome pathways, respectively. The downregulation of HIF- $1 \alpha$ reverses the chemoresistance of ovarian cancer cells to cisplatin (115). Wogonin is a main component of S. baicalensis Georgi. It has been demonstrated that FV-429, a derivative of wogonin, has antitumoural activity (116). In hypoxic ovarian cancer cells, FV429 can interfere with the expression and phosphorylation of cScr, inhibit the translocation and DNA binding activity of STAT3, and inhibit HIF-1 $\alpha$ expression, causing the downregulation of HK2 and VEGF and enhancement of the G2/M arrest induced by paclitaxel (117) (Figure 4).

The total triterpenoid saponins extracted from the seeds of Camellia sinensis contribute to the antiangiogenetic effect on ovarian cancer by reducing VEGF expression in a HIF-1 $\alpha$ dependent manner (118). Theasaponin E1, as the main component of the C. sinensis extract (119), can reduce the expression of Dll4 and Jagged1 to inhibit the Notch1 pathway, and the Notch1 pathway is known to inactivate ATM in other studies. The activation of ATM upregulates the expression of PTEN and reduces the phosphorylation of AKT and the downstream proteins of AKT pathways, such as HIF-1 $\alpha$, thereby inhibiting the expression of VEGF (120, 121) (Figure 4).

\section{Compounds Extracted From Animal}

Not only compounds extracted from plants, but also animal can inhibit HIF-1 $\alpha$ expression and exhibit the ability to suppress ovarian cancer progression. Bufalin, which is obtained from the skin and parotid venom glands of toads, is a common traditional Chinese medicine. Bufalin has been proven to protect against various kinds of cancers, including ovarian cancer $(122,123)$. Bufalin did not affect the viability of normal ovarian epithelial cells even at doses as high as $40 \mu \mathrm{M}$ but significantly restrained the growth of the OAW28 cell line (an ovarian epithelial carcinoma cell line). In ovarian cancer cells, bufalin could downregulation of HIF- $1 \alpha$ via inhibiting the phosphorylation of mTOR and then inducing the suppression cell growth and migration (124) (Figure 4).

\section{Synthetic Drugs}

Currently, cisplatin is the first-line chemotherapy drug for a variety of malignant tumours and HIF- $1 \alpha$ is associated with cisplatin-resistance (124).However, in the cisplatin-sensitive ovarian cancer cells, cisplatin promotes HIF-1 $\alpha$ degradation via the proteasome pathway, induces the downregulation of $\mathrm{LDH}-\mathrm{A}$ expression, and then increases the level of reactive oxygen species (ROS) by inducing the cells to produce ATP through oxidative phosphorylation, which modulates cisplatin resistance and promotes the death of ovarian cancer cells (125127) (Figure 4).

Although metformin is a common agent for diabetes treatment, a study has shown that metformin can inhibit the expression of HIF-1 $\alpha$ and the growth of ovarian cancer cells (128). As previously noted, mesothelial cells in the tumour microenvironment of ovarian cancer play crucial roles in tumour progression (81). In addition to its influence on cancer cells alone, in mesothelial cells, metformin induces the expression of the tricarboxylic acid (TCA) enzyme succinyl CoA ligase (SUCLG2), leading to metabolic reprogramming and reducing the production of succinic acid. As an inhibitor of PDH, succinic acid causes HIF- $1 \alpha$ degradation. In addition, metformin induces the downregulation of TGF-1 $\beta$ in ovarian cancer cells, and the reduction in secreted TGF-1 $\beta$ restores PDH activity, leading to increases in HIF- $1 \alpha$ degradation. In summary, the reduced expression of HIF- $1 \alpha$ results in the downregulation of IL-8 and hinders the invasion of ovarian cancer cells (129). Considering that IL-8 can promote ovarian cancer progression through several pathways (130-132), it is recommended that further investigation be directed towards the pathways by which metformin mediates its effects on ovarian cancer (129) (Figure 4).

SC-144, a novel synthetic agent, can target gp130 and kill ovarian cancer cells (133). A genome-wide bromouridine sequencing (Bru-seq) analysis showed that longer exposure to SC144 led to lower HIF-1 $\alpha$ expression but a higher hypoxiainducible factor antisense (HIF-1 $\alpha$-AS) level (134). Considering that HIF- $1 \alpha$-AS downregulates the expression of HIF-1 $\alpha$ (135) and because HIF-1 $\alpha$ plays a role in the progression of cancer, we speculate that SC-144 inhibits the proliferation of ovarian cancer, at least to some extent, via the HIF- $1 \alpha$-AS/HIF- $1 \alpha$ axis. However, the function of HIF-1 $\alpha$-AS in malignant tumours is complicated $(136,137)$, and data on the role of HIF-1 $\alpha$-AS in ovarian cancer have not been reported. Hence, future investigation into the function of the HIF- $1 \alpha$-AS/HIF- $1 \alpha$ axis in ovarian cancer is recommended (Figure 4).

\section{Noncoding RNAs}

MiRNAs belong to the family of noncoding RNAs, and some miRNAs serve as a sponge to regulate the expression of genes and influence the development of cancer. Transfection of miR195-5p can inhibit PSAT1 directly because this miRNA interacts with the 3'-UTR of PSAT1 mRNA, thus suppressing the phosphorylation of $\beta$-catenin and GSK3 $\beta$, downregulating the expression of HIF- $1 \alpha$ and VEGF, inducing apoptosis and reducing cisplatin chemoresistance (138). MiR-138 is downregulated in ovarian cancer, especially in invasive cell sublines, and acts as a cancer suppressor. Overexpression of miR-138 downregulates HIF-1 $\alpha$ expression and induces the inhibition of Slug (139), which is associated with ovarian cancer metastasis (140) (Figure 4). 


\section{DRUG CLINICAL TRIALS OF THE HIF- $1 \alpha$ INHIBITORS IN SOLID MALIGNANT TUMOURS}

\section{2-Methoxyestradiol (2ME2)}

$2 \mathrm{ME} 2$ is a derivative of estradiol and has been proven to downregulate HIF- $1 \alpha$ at the posttranscriptional level (153). In 2009 , a phase II study of 2ME2 administered at a dose of $1000 \mathrm{mg}$ four times per day in recurrent, platinum-resistant ovarian cancer patients reported that no objective response was observed in the study, but 7 out of 18 patients had stable disease and 2 of them had stable disease for more than 12 months (142). In taxane-refractory, metastatic castrationresistant prostate cancer patients, $2 \mathrm{ME} 2$ did not benefit patients with a poor PFS at 6 months rate (only 5.35\%) (141). In another phase II clinical trial, patients were divided into two arms (arm A,2ME2 alone, $\mathrm{n}=10$; arm B, 2ME2 combined with sunitinib malate, $n=7)$. However, owing to intolerance toxicities that may be caused by a high dose of 2ME2 (1500 mg three times per day), 6 patients were required to quite the study, and no objective responses were observed in the two arms (143) (Table 2).

\section{Tanespimycin}

Heat-shock protein 90 could stabilize the HIF- $1 \alpha$ protein by inhibiting the ubiquitination and proteasomal degradation of HIF-1 $\alpha$ (154). Tanespimycin is a heat-shock protein 90 inhibitor (155). In 2006, 20 renal cell cancer (RCC) patients were enrolled in a phase II study that focused on the efficacy and toxicities of tanespimycin. Five of eight papillary renal cell cancer patients and 9 of 12 patients had stable disease, but none of them achieved complete or partial response. Thirty percent of patients required a reduced dose because of toxicities (144). In hormone-refractory metastatic prostate cancer patients, none achieved a PSA response and the 6-month OS rate was $71 \%$ (145) (Table 2).

\section{Vorinostat}

Vorinostat inhibits HIF- $1 \alpha$ protein expression at the translational level (156).In 2014, a total of 32 melanoma patients were given vorinostat, 18 of whom had stable disease with a median PFS of 5 months or partial response. For the patients with partial response, one remained for 7 cycles, and the other remained for 5 cycles; each cycle lasted 28 days. In addition, two patients who had stable disease had dramatic responses (33-50\% shrinkage), which lasted only approximately

TABLE 2 | Drug clinical trials with HIF- $1 \alpha$ inhibitors.

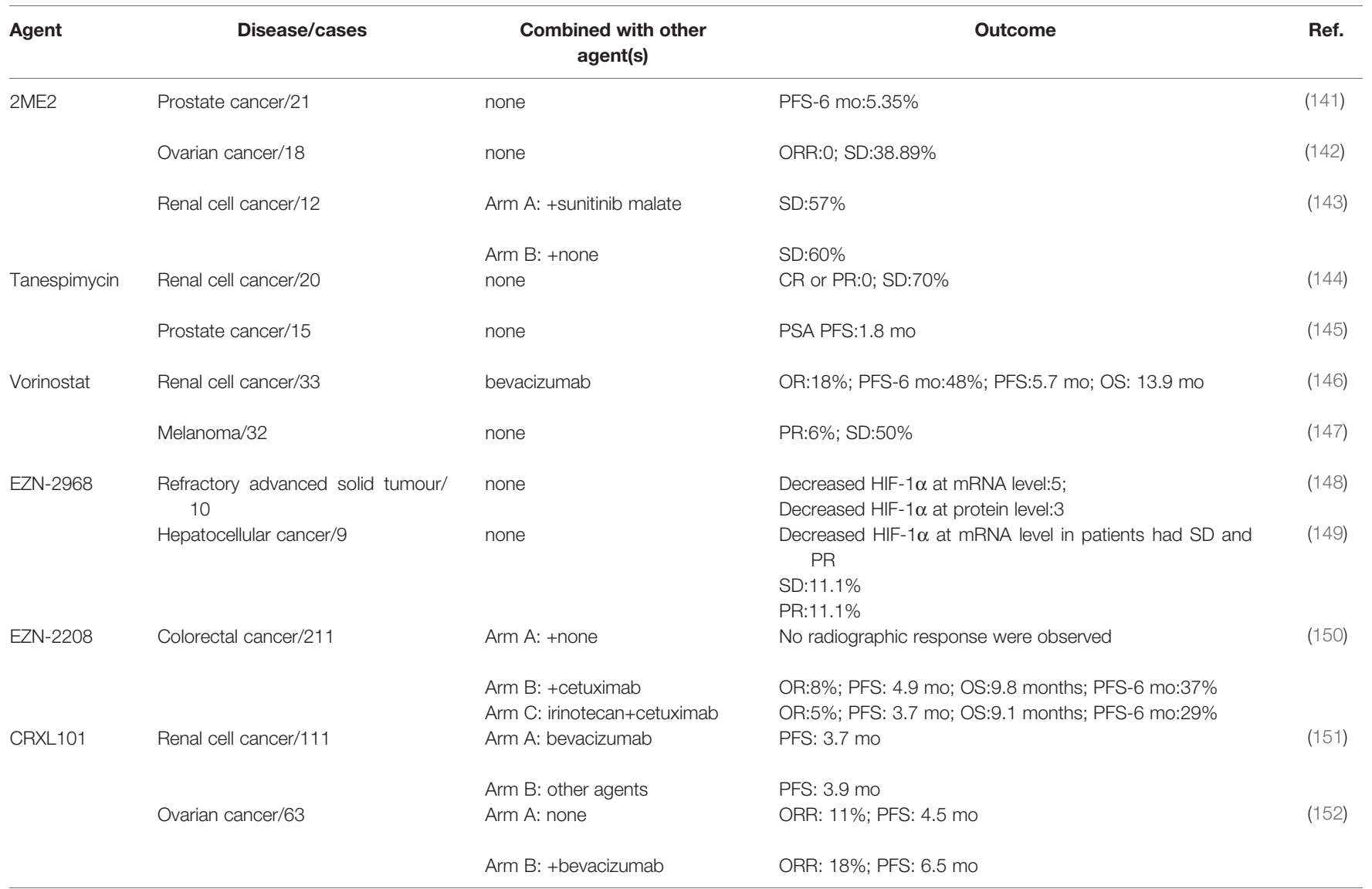

PFS, progression-free survival; mo, months; PFS-6 mo, progression-free survival at 6 months; ORR, overall response rate; CR, complete response; PR, partial response. 
A

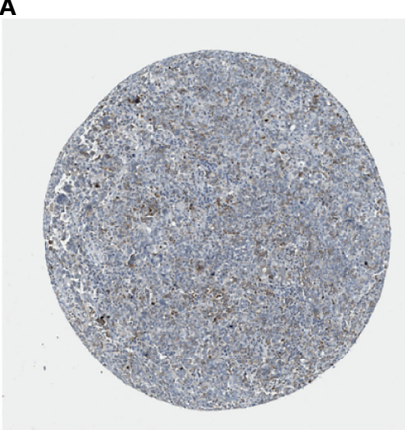

Ovarian endometroid carcinoma
B

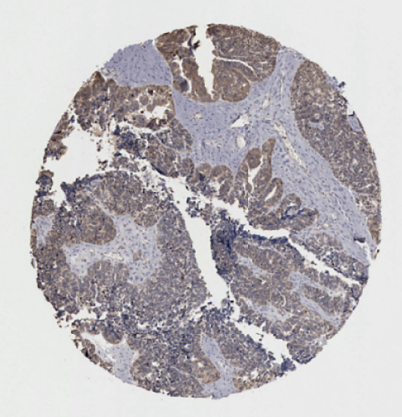

Ovarian serous carcinoma c

FIGURE 5 | (A-C) HIF-1 $\alpha$ expression in ovarian cancer (available from http://v13.proteinatlas.org/ENSG00000100644-HIF1A/cancer/tissue/ovarian+cancer\#img) is higher compared with that in normal ovarian tissue (available from https://www.proteinatlas.org/ENSG00000100644-HIF1A/tissue/ovary\#img). The brown staining indicates the presence of HIF-1 $\alpha$.

two months. The time is too short to be confirmed as a response (147). In 33 clear-cell renal cell carcinoma patients who received vorinostat combined with bavacizumab, the PFS at 6 months was 48\%. The median PFS was 5.7 months, while the OS was 13.9 months. Six objective responses were observed, and 19 patients had stable disease (146) (Table 2).

\section{EZN-2968}

EZN-2968 is an RNA antagonist that can specifically bind to and inhibit the expression of HIF- $1 \alpha$ mRNA to downregulate HIF$1 \alpha$ protein expression in cancer cells (157). In a pilot trial of patients with refractory advanced solid tumours, EZN-2968 could downregulated HIF-1 $\alpha$ expression at the mRNA (5/6) and protein (3/5) levels in some patients (148). In a phase Ib trial, 2 of 9 advanced hepatocellular cancers had a partial response or stable disease, and the HIF- $1 \alpha$ mRNA was downregulated in the cancer tissue (149) (Table 2).

\section{EZN-2208}

EZN-2208 is a soluble derivative of SN-38, which is an active metabolite of irinotecan (158).EZN-2208 could inhibit the expression of HIF- $1 \alpha$ mRNA and protein, which is superior to irinotecan, thus controlling the angiogenic response (159). A total of 211 advanced colorectal cancer patients were enrolled in a phase II study, and were divided into 3 arms(arm A: EZN-2208, for KRAS-mutant patients; arm B: EZN-2208+cetuximab, for KRAS-wild-type patients; arm C: irinotecan+cetuximab, for KRAS-Wild type patients). When comparing the OR, OS, PFS and PFS at 6 months rate between arm B and arm C, arm B showed slightly superior efficacy. However, there was no statistically significant difference between these two arms (150) (Table 2).

\section{CRLX101}

Antiangiogenic therapy induced increased HIF-1 $\alpha$ expression, and CRLX101 reduced the HIF-1 $\alpha$ expression when combined with bevacizumab in animal models (160). In a phase II study of 63 recurrent ovarian cancer patients, 29 patients who received single agent CRLX101 had an overall response rate (ORR) of $11 \%$. When 34 patients were treated CRLX101 combined with bavacizumab, the ORR was increased to $18 \%$ (152). However, in another phase II study of 111 advanced renal cell cancer patients, CRLX101 combined with bevacizumab did not show any added benefit to patients compared with standard treatment (151) (Table 2).

\section{CONCLUSION AND FUTURE PROSPECTS}

HIF- $1 \alpha$ has been proven to be overexpressed in more than $70 \%$ of human cancers, including ovarian cancer (Figures $\mathbf{5 A - C}$ ) $(161,162)$, and occupies a central position in multiple pathways of ovarian cancer. HIF- $1 \alpha$ acts as a transcription factor to regulate a variety of proteins, thereby promoting the development of ovarian tumours. In the ovarian cancer microenvironment, various factors can also regulate the expression of HIF-1 $\alpha$ expression in nontumour cells and affect the malignant biological properties of tumour cells.

On the basis of the proposed concept of precision medicine, targeted drugs developed based on tumour characteristics have emerged in an endless stream, and among these drugs, antiangiogenic agents mainly target VEGF, thereby inhibiting a series of pathophysiological processes regulated by VEGF and benefiting patients with tumours such as ovarian or breast cancer $(163,164)$. Because VEGF is a downstream gene of HIF-1 $\alpha$, VEGF expression is decreased when the expression or function of HIF- $1 \alpha$ is inhibited $(55,113,114,118)$, and HIF- $1 \alpha$ can regulate the expression of other genes that promote tumour progression. Therefore, we concluded that targeting HIF- $1 \alpha$ may effectively inhibit tumour development. Studies have shown that, regardless of whether a therapy is based on monomeric components extracted from plants or classic drugs that have been clinically used in cancer treatment for many years, a therapy can inhibit ovarian cancer progression after directly or indirectly inhibiting HIF- $1 \alpha$. 
Recently, clinical trials have been conducted to evaluated drugs that could modulate HIF-1 $\alpha$ expression in many kinds of solid tumours. However, the efficacy has been limited and varied in these trials, and only EZN-2968 could combined with the HIF- $1 \alpha$ mRNA to regulate HIF- $1 \alpha$ protein expression. The remaining drugs all regulated HIF- $1 \alpha$ indirectly. It is suggested to explore new drugs that could interact with HIF- $1 \alpha$ protein directly. In addition, almost all of the drugs were taken orally. Hypoxia occurs in tumours and is associated with the newly formed abnormal microvessels (165), and chemotherapy drugs cannot reach the tumour site due to the high interstitial fluid pressure caused by the abnormal microvessels (166). This situation means that HIF- $1 \alpha$ inhibitors may not influence the cells that produce HIF-1 $\alpha$. It is not only recommended to develop new agents that target HIF- $1 \alpha$ directly but also attach importance to the delivery method of drugs so that ideal drug concentrations can be reached. In a clinical trial of ovarian cancer, the ORR and PFS were superior in the bevacizumab+HIF- $1 \alpha$ inhibitor group to the HIF-1 $\alpha$ inhibitor group (152). We may infer that in the application of HIF-1 $\alpha$ inhibitor to treat ovarian cancer, it is better to combine HIF- $1 \alpha$ inhibitor with other agents.

In view of the tremendous heterogeneity between different types of tumours, the unsatisfactory results found in cancers now do not necessarily indicate a failure of these kinds of agents in the future. Clinical trials have shown that combining the HIF-1 $\alpha$

\section{REFERENCES}

1. Sung H, Ferlay J, Siegel RL, Laversanne M, Soerjomataram I, Jemal A, et al. Global Cancer Statistics 2020: GLOBOCAN Estimates of Incidence and Mortality Worldwide for 36 Cancers in 185 Countries. CA Cancer J Clin (2021) 71(3):209-49. doi: 10.3322/caac.21660

2. Torre LA, Trabert B, DeSantis CE, Miller KD, Samimi G, Runowicz CD, et al. Ovarian Cancer Statistics, 2018. CA Cancer J Clin (2018) 68(4):284-96. doi: 10.3322/caac. 21456

3. Lheureux S, Gourley C, Vergote I, Oza AM. Epithelial Ovarian Cancer. Lancet (2019) 393(10177):1240-53. doi: 10.1016/s0140-6736(18)32552-2

4. Siegel RL, Miller KD, Jemal A. Cancer Statistics, 2020. CA Cancer J Clin (2020) 70(1):7-30. doi: 10.3322/caac.21590

5. Bejarano L, Jordao MJC, Joyce JA. Therapeutic Targeting of the Tumor Microenvironment. Cancer Discovery (2021) 11(4):933-59. doi: 10.1158/ 2159-8290.CD-20-1808

6. Hede K. Environmental Protection: Studies Highlight Importance of Tumor Microenvironment. J Natl Cancer Inst (2004) 96(15):1120-1. doi: 10.1093/ jnci/96.15.1120

7. Rofstad EK, Gaustad JV, Egeland TA, Mathiesen B, Galappathi K. Tumors Exposed to Acute Cyclic Hypoxic Stress Show Enhanced Angiogenesis, Perfusion and Metastatic Dissemination. Int J Cancer (2010) 127(7):153546. doi: 10.1002/ijc.25176

8. Yang Y, Yang Y, Yang J, Zhao X, Wei X. Tumor Microenvironment in Ovarian Cancer: Function and Therapeutic Strategy. Front Cell Dev Biol (2020) 8:758. doi: 10.3389/fcell.2020.00758

9. Vaupel P, Kallinowski F, Okunieff P. Blood Flow, Oxygen and Nutrient Supply, and Metabolic Microenvironment of Human Tumors: A Review. Cancer Res (1989) 49(23):6449-65.

10. Harris A. Hypoxia-a Key Regulatory Factor in Tumour Growth. JNRC (2002) 2(1):38-47. doi: 10.1038/nrc704

11. Liu Z, Wu Z, Fan Y, Fang Y. An Overview of Biological Research on Hypoxia-Inducible Factors (HIFs). Endokrynol Pol (2020) 71(5):432-40. doi: 10.5603/EP.a2020.0064

12. Semenza G, Wang G. A Nuclear Factor Induced by Hypoxia via De Novo Protein Synthesis Binds to the Human Erythropoietin Gene Enhancer at a inhibitors and bevacizumab may benefit ovarian cancer patients (152). Further exploration into the efficacy of HIF- $1 \alpha$ inhibitors in ovarian cancers is necessary. In addition, since HIF- $1 \alpha$ is a transcription factor that facilitates both malignant and normal cell adaptation to hypoxic stress in the internal environment, it is particularly important to design drugs targeting only HIF- $1 \alpha$ expressed in tumours to reduce the adverse effects.

\section{AUTHOR CONTRIBUTIONS}

$\mathrm{HZ}$ and XW contributed to the conception, design and drafting of the manuscript. Z-wD, T-mX, and X-jW contributed to data collection and drafting the manuscript. WL and J-lG prepared the figures. JL prepared the tables. All authors approved the final version for submission. HZ oversaw the study.

\section{FUNDING}

This study was supported by the Health Special Project Founds of Jilin Province (Grant No. 2020SCZT042), and the Jilin Science and Technology Funds, China (Grant No. 20210204025YY).
Site Required for Transcriptional Activation. JM Biol c (1992) 12(12):544754. doi: $10.1128 / \mathrm{mcb} .12 .12 .5447$

13. Ema M, Taya S, Yokotani N, Sogawa K, Matsuda Y, Fujii-Kuriyama Y. A Novel bHLH-PAS Factor With Close Sequence Similarity to HypoxiaInducible Factor 1alpha Regulates the VEGF Expression and is Potentially Involved in Lung and Vascular Development. Proc Natl Acad Sci USA (1997) 94(9):4273-8. doi: 10.1073/pnas.94.9.4273

14. Gu Y, Moran S, Hogenesch J, Wartman L, Bradfield C. Molecular Characterization and Chromosomal Localization of a Third Alpha-Class Hypoxia Inducible Factor Subunit, HIF3alpha. JGe (1998) 7(3):205-13.

15. Loboda A, Jozkowicz A, Dulak J. HIF-1 Versus HIF-2-is One More Important Than the Other? Vascul Pharmacol (2012) 56(5-6):245-51. doi: 10.1016/j.vph.2012.02.006

16. Semenza GL. Targeting HIF-1 for Cancer Therapy. Nat Rev Cancer (2003) 3 (10):721-32. doi: $10.1038 / \mathrm{nrc1} 187$

17. Loboda A, Jozkowicz A, Dulak J. HIF-1 and HIF-2 Transcription FactorsSimilar But Not Identical. Mol Cells (2010) 29(5):435-42. doi: 10.1007/ s10059-010-0067-2

18. Ramakrishnan SK, Shah YM. Role of Intestinal HIF-2alpha in Health and Disease. Annu Rev Physiol (2016) 78:301-25. doi: 10.1146/annurev-physiol-021115-105202

19. Erbel PJ, Card PB, Karakuzu O, Bruick RK, Gardner KH. Structural Basis for PAS Domain Heterodimerization in the Basic Helix-Loop-Helix-PAS Transcription Factor Hypoxia-Inducible Factor. Proc Natl Acad Sci USA (2003) 100(26):15504-9. doi: 10.1073/pnas.2533374100

20. Masoud GN, Li W. HIF-1alpha Pathway: Role, Regulation and Intervention for Cancer Therapy. Acta Pharm Sin B (2015) 5(5):378-89. doi: 10.1016/ j.apsb.2015.05.007

21. Wu D, Potluri N, Lu J, Kim Y, Rastinejad F. Structural Integration in HypoxiaInducible Factors. Nature (2015) 524(7565):303-8. doi: 10.1038/nature14883

22. Chapman-Smith A, Lutwyche JK, Whitelaw ML. Contribution of the Per/ Arnt/Sim (PAS) Domains to DNA Binding by the Basic Helix-Loop-Helix PAS Transcriptional Regulators. J Biol Chem (2004) 279(7):5353-62. doi: $10.1074 /$ jbc.M310041200

23. Scheuermann TH, Yang J, Zhang L, Gardner KH, Bruick RK. HypoxiaInducible Factors Per/ARNT/Sim Domains: Structure and Function. Oxygen Biol Hypoxia (2007) 435:1-24. doi: 10.1016/S0076-6879(07)35001-5 
24. Dufies M, Verbiest A, Cooley LS, Ndiaye PD, He X, Nottet N, et al. Plk1, Upregulated by HIF-2, Mediates Metastasis and Drug Resistance of Clear Cell Renal Cell Carcinoma. Commun Biol (2021) 4(1):166. doi: 10.1038/ s42003-021-01653-w

25. Chen Y, Zhang B, Bao L, Jin L, Yang M, Peng Y, et al. ZMYND8 Acetylation Mediates HIF-Dependent Breast Cancer Progression and Metastasis. J Clin Invest (2018) 128(5):1937-55. doi: 10.1172/JCI95089

26. Seeber LM, Horree N, Vooijs MA, Heintz AP, van der Wall E, Verheijen RH, et al. The Role of Hypoxia Inducible Factor-1alpha in Gynecological Cancer. Crit Rev Oncol Hematol (2011) 78(3):173-84. doi: 10.1016/j.critrevonc.2010.05.003

27. Birner P, Schindl M, Obermair A, Breitenecker G, Oberhuber G. Expression of Hypoxia-Inducible Factor 1alpha in Epithelial Ovarian Tumors: Its Impact on Prognosis and on Response to Chemotherapy. Clin Cancer Res (2001) 7(6):1661-8.

28. Nakai H, Watanabe Y, Ueda H, Hoshiai H. Hypoxia Inducible Factor 1Alpha Expression as a Factor Predictive of Efficacy of Taxane/Platinum Chemotherapy in Advanced Primary Epithelial Ovarian Cancer. Cancer Lett (2007) 251(1):164-7. doi: 10.1016/j.canlet.2006.11.017

29. Daponte A, Ioannou M, Mylonis I, Simos G, Minas M, Messinis IE, et al. Prognostic Significance of Hypoxia-Inducible Factor 1 Alpha(HIF-1 Alpha) Expression in Serous Ovarian Cancer: An Immunohistochemical Study. BMC Cancer (2008) 8:335. doi: 10.1186/1471-2407-8-335

30. Chen Y, Zhang L, Pan Y, Ren X, Hao Q. Over-Expression of Semaphorin4d, Hypoxia-Inducible Factor-1alpha and Vascular Endothelial Growth Factor is Related to Poor Prognosis in Ovarian Epithelial Cancer. Int J Mol Sci (2012) 13(10):13264-74. doi: 10.3390/ijms131013264

31. Braicu EI, Luketina H, Richter R, Cacsire Castillo-Tong D, Lambrechts S, Mahner S, et al. HIFlalpha is an Independent Prognostic Factor for Overall Survival in Advanced Primary Epithelial Ovarian Cancer - a Study of the OVCAD Consortium. Onco Targets Ther (2014) 7:1563-9. doi: 10.2147/OTT.S65373

32. Shen W, Li HL, Liu L, Cheng JX. Expression Levels of PTEN, HIF-1 $\alpha$, and VEGF as Prognostic Factors in Ovarian Cancer. Eur Rev Med Pharmacol Sci (2017) 21(11):2596-603.

33. Alabiad M, Harb O, Mandour D, Hemeda R, ZA R, El-Taher A, et al. Prognostic and Clinicopathological Implications of Expression of Beclin-1 and Hypoxia-Inducible Factor 1alpha in Serous Ovarian Carcinoma: An Immunohistochemical Study. Pol J Pathol (2021) 72(1):23-38. doi: 10.5114/ pjp.2021.106441

34. Lidgren A, Hedberg Y, Grankvist K, Rasmuson T, Vasko J, Ljungberg B. The Expression of Hypoxia-Inducible Factor 1alpha Is a Favorable Independent Prognostic Factor in Renal Cell Carcinoma. Clin Cancer Res (2005) 11 (3):1129-35.

35. Fillies T, Werkmeister R, van Diest PJ, Brandt B, Joos U, Buerger H. HIF1Alpha Overexpression Indicates a Good Prognosis in Early Stage Squamous Cell Carcinomas of the Oral Floor. BMC Cancer (2005) 5:84. doi: 10.1186/ 1471-2407-5-84

36. Kurokawa T, Miyamoto M, Kato K, Cho Y, Kawarada Y, Hida Y, et al. Overexpression of Hypoxia-Inducible-Factor 1alpha(HIF-1alpha) in Oesophageal Squamous Cell Carcinoma Correlates With Lymph Node Metastasis and Pathologic Stage. Br J Cancer (2003) 89(6):1042-7. doi: 10.1038/sj.bjc.6601186

37. Osada R, Horiuchi A, Kikuchi N, Yoshida J, Hayashi A, Ota M, et al. Expression of Hypoxia-Inducible Factor 1alpha, Hypoxia-Inducible Factor 2alpha, and Von Hippel-Lindau Protein in Epithelial Ovarian Neoplasms and Allelic Loss of Von Hippel-Lindau Gene: Nuclear Expression of Hypoxia-Inducible Factor 1alpha is an Independent Prognostic Factor in Ovarian Carcinoma. Hum Pathol (2007) 38 (9):1310-20. doi: 10.1016/j.humpath.2007.02.010

38. Jin Y, Wang H, Liang X, Ma J, Wang Y. Pathological and Prognostic Significance of Hypoxia-Inducible Factor 1alpha Expression in Epithelial Ovarian Cancer: A Meta-Analysis. Tumour Biol (2014) 35(8):8149-59. doi: $10.1007 / \mathrm{s} 13277-014-2059-\mathrm{x}$

39. Liu J, Zhang C, Hu W, Feng Z. Tumor Suppressor P53 and Metabolism. J Mol Cell Biol (2019) 11(4):284-92. doi: 10.1093/jmcb/mjy070

40. Ferreira CG, Tolis C, Giaccone G. P53 and Chemosensitivity. Ann Oncol (1999) 10(9):1011-21. doi: 10.1023/a:1008361818480

41. Ramezani T, Nabiuni M, Baharara J, Parivar K, Namvar F. Sensitization of Resistance Ovarian Cancer Cells to Cisplatin by Biogenic Synthesized Silver Nanoparticles Through P53 Activation. Iran J Pharm Res (2019) 18(1):222-31.
42. Zhang Y, Yapryntseva MA, Vdovin A, Maximchik P, Zhivotovsky B, Gogvadze V. Modeling Hypoxia Facilitates Cancer Cell Survival Through Downregulation of P53 Expression. Chem Biol Interact (2021) 345:109553. doi: 10.1016/j.cbi.2021.109553

43. Fraser M, Bai T, Tsang BK. Akt Promotes Cisplatin Resistance in Human Ovarian Cancer Cells Through Inhibition of P53 Phosphorylation and Nuclear Function. Int J Cancer (2008) 122(3):534-46. doi: 10.1002/ijc.23086

44. Yan X, Fraser M, Qiu Q, Tsang BK. Over-Expression of PTEN Sensitizes Human Ovarian Cancer Cells to Cisplatin-Induced Apoptosis in a P53Dependent Manner. Gynecol Oncol (2006) 102(2):348-55. doi: 10.1016/ j.ygyno.2005.12.033

45. Parmakhtiar B, Burger RA, Kim JH, Fruehauf JP. HIF Inactivation of P53 in Ovarian Cancer Can Be Reversed by Topotecan, Restoring Cisplatin and Paclitaxel Sensitivity. Mol Cancer Res (2019) 17(8):1675-86. doi: 10.1158/ 1541-7786.MCR-18-1109

46. Sanchez-Puig N, Veprintsev DB, Fersht AR. Binding of Natively Unfolded HIF-1alpha ODD Domain to P53. Mol Cell (2005) 17(1):11-21. doi: 10.1016/j.molcel.2004.11.019

47. Taher MY, Davies DM, Maher J. The Role of the Interleukin (IL)-6/IL-6 Receptor Axis in Cancer. Biochem Soc Trans (2018) 46(6):1449-62. doi: 10.1042/BST20180136

48. Berek JS, Chung C, Kaldi K, Watson JM, Knox RM, Martínez-Maza O. Serum Interleukin-6 Levels Correlate With Disease Status in Patients With Epithelial Ovarian Cancer. Am J Obstet Gynecol (1991) 164(4):1038-43. doi: 10.1016/0002-9378(91)90582-c

49. Lane D, Matte I, Rancourt C, Piche A. Prognostic Significance of IL-6 and IL-8 Ascites Levels in Ovarian Cancer Patients. BMC Cancer (2011) 11:210. doi: 10.1186/1471-2407-11-210

50. Dijkgraaf EM, Welters MJ, Nortier JW, van der Burg SH, Kroep JR. Interleukin-6/Interleukin-6 Receptor Pathway as a New Therapy Target in Epithelial Ovarian Cancer. Curr Pharm Des (2012) 18(25):3816-27. doi: 10.2174/138161212802002797

51. Xu K, Zhan Y, Yuan Z, Qiu Y, Wang H, Fan G, et al. Hypoxia Induces Drug Resistance in Colorectal Cancer Through the HIF-1alpha/miR-338-5p/IL-6 Feedback Loop. Mol Ther (2019) 27(10):1810-24. doi: 10.1016/j.ymthe.2019.05.017

52. Han X, Lu Y, Li X, Xia L, Wen H, Feng Z, et al. Overexpression of NPTX2 Promotes Malignant Phenotype of Epithelial Ovarian Carcinoma via IL6JAK2/STAT3 Signaling Pathway Under Hypoxia. Front Oncol (2021) 11:643986. doi: 10.3389/fonc.2021.643986

53. Xu S, Yu C, Ma X, Li Y, Shen Y, Chen Y, et al. IL-6 Promotes Nuclear Translocation of HIF-1alpha to Aggravate Chemoresistance of Ovarian Cancer Cells. Eur J Pharmacol (2021) 894:173817. doi: 10.1016/j.ejphar.2020.173817

54. Shih CH, Chuang LL, Tsai MH, Chen LH, Chuang EY, Lu TP, et al. Hypoxia-Induced MALAT1 Promotes the Proliferation and Migration of Breast Cancer Cells by Sponging MiR-3064-5p. Front Oncol (2021) 11:658151. doi: 10.3389/fonc.2021.658151

55. Wang Y, Huang Y, Liu H, Su D, Luo F, Zhou F. Long Noncoding RNA CDKN2B-AS1 Interacts With miR-411-3p to Regulate Ovarian Cancer In Vitro and In Vivo Through HIF-1a/VEGF/P38 Pathway. Biochem Biophys Res Commun (2019) 514(1):44-50. doi: 10.1016/j.bbrc.2019.03.141

56. Dong L, Cao X, Luo Y, Zhang G, Zhang D. A Positive Feedback Loop of lncRNA DSCR8/miR-98-5p/STAT3/HIF-1alpha Plays a Role in the Progression of Ovarian Cancer. Front Oncol (2020) 10:1713. doi: 10.3389/ fonc. 2020.01713

57. Ediriweera MK, Tennekoon KH, Samarakoon SR. Role of the PI3K/AKT/ mTOR Signaling Pathway in Ovarian Cancer: Biological and Therapeutic Significance. Semin Cancer Biol (2019) 59:147-60. doi: 10.1016/ j.semcancer.2019.05.012

58. Huang J, Gao L, Li B, Liu C, Hong S, Min J, et al. Knockdown of HypoxiaInducible Factor 1alpha (HIF-1alpha) Promotes Autophagy and Inhibits Phosphatidylinositol 3-Kinase (PI3K)/AKT/Mammalian Target of Rapamycin (mTOR) Signaling Pathway in Ovarian Cancer Cells. Med Sci Monit (2019) 25:4250-63. doi: 10.12659/MSM.915730

59. Ataie-Kachoie P, Pourgholami MH, Bahrami BF, Badar S, Morris DL. Minocycline Attenuates Hypoxia-Inducible Factor-1alpha Expression Correlated With Modulation of P53 and AKT/mTOR/p70S6K/4E-BP1 Pathway in Ovarian Cancer: In Vitro and In Vivo Studies. Am J Cancer Res (2015) 5(2):575-88. 
60. Gao N, Nester RA, Sarkar MA. 4-Hydroxy Estradiol But Not 2-Hydroxy Estradiol Induces Expression of Hypoxia-Inducible Factor 1alpha and Vascular Endothelial Growth Factor A Through Phosphatidylinositol 3Kinase/Akt/FRAP Pathway in OVCAR-3 and A2780-CP70 Human Ovarian Carcinoma Cells. Toxicol Appl Pharmacol (2004) 196(1):124-35. doi: 10.1016/j.taap.2003.12.002

61. Zhang T, Ye L, Han L, He Q, Zhu J. Knockdown of HVEM, a Lymphocyte Regulator Gene, in Ovarian Cancer Cells Increases Sensitivity to Activated T Cells. Oncol Res (2016) 24(3):189-96. doi: 10.3727/096504016X14641336229602

62. Duan L, Tao J, Yang X, Ye L, Wu Y, He Q, et al. HVEM/HIF-1alpha Promoted Proliferation and Inhibited Apoptosis of Ovarian Cancer Cells Under Hypoxic Microenvironment Conditions. J Ovarian Res (2020) 13 (1):40. doi: 10.1186/s13048-020-00646-3

63. Liberti MV, Locasale JW. The Warburg Effect: How Does it Benefit Cancer Cells? Trends Biochem Sci (2016) 41(3):211-8. doi: 10.1016/j.tibs.2015.12.001

64. Wang S, Zhang Y, Cai Q, Ma M, Jin LY, Weng M, et al. Circular RNA FOXP1 Promotes Tumor Progression and Warburg Effect in Gallbladder Cancer by Regulating PKLR Expression. Mol Cancer (2019) 18(1):145. doi: 10.1186/s12943-019-1078-Z

65. Qiu Y, Zhu H, Xu D, Feng Q, Wen C, Du Y, et al. RING-Finger Protein 6 Enhances C-Myc-Mediated Warburg Effect by Promoting MAD1 Degradation to Facilitate Pancreatic Cancer Metastasis. Am J Cancer Res (2021) 11(5):2025-43.

66. Peng X, Gong F, Chen Y, Jiang Y, Liu J, Yu M, et al. Autophagy Promotes Paclitaxel Resistance of Cervical Cancer Cells: Involvement of Warburg Effect Activated Hypoxia-Induced Factor 1-Alpha-Mediated Signaling. Cell Death Dis (2014) 5:e1367. doi: 10.1038/cddis.2014.297

67. Tyagi K, Mandal S, Roy A. Recent Advancements in Therapeutic Targeting of the Warburg Effect in Refractory Ovarian Cancer: A Promise Towards Disease Remission. Biochim Biophys Acta Rev Cancer (2021) 1876 (1):188563. doi: 10.1016/j.bbcan.2021.188563

68. Nagao A, Kobayashi M, Koyasu S, Chow CCT, Harada H. HIF-1-Dependent Reprogramming of Glucose Metabolic Pathway of Cancer Cells and Its Therapeutic Significance. Int J Mol Sci (2019) 20(2):238. doi: 10.3390/ ijms 20020238

69. Icard P, Shulman S, Farhat D, Steyaert JM, Alifano M, Lincet H. How the Warburg Effect Supports Aggressiveness and Drug Resistance of Cancer Cells? Drug Resist Updat (2018) 38:1-11. doi: 10.1016/j.drup.2018.03.001

70. Miranda F, Mannion D, Liu S, Zheng Y, Mangala LS, Redondo C, et al. SaltInducible Kinase 2 Couples Ovarian Cancer Cell Metabolism With Survival at the Adipocyte-Rich Metastatic Niche. Cancer Cell (2016) 30(2):273-89. doi: 10.1016/j.ccell.2016.06.020

71. Zhao J, Zhang X, Gao T, Wang S, Hou Y, Yuan P, et al. SIK2 Enhances Synthesis of Fatty Acid and Cholesterol in Ovarian Cancer Cells and Tumor Growth Through PI3K/Akt Signaling Pathway. Cell Death Dis (2020) 11 (1):25. doi: 10.1038/s41419-019-2221-x

72. Gao T, Zhang X, Zhao J, Zhou F, Wang Y, Zhao Z, et al. SIK2 Promotes Reprogramming of Glucose Metabolism Through PI3K/AKT/HIF-1alpha Pathway and Drp1-Mediated Mitochondrial Fission in Ovarian Cancer. Cancer Lett (2020) 469:89-101. doi: 10.1016/j.canlet.2019.10.029

73. Contreras-Baeza Y, Sandoval PY, Alarcon R, Galaz A, Cortes-Molina F, Alegria $\mathrm{K}$, et al. Monocarboxylate Transporter 4 (MCT4) is a High Affinity Transporter Capable of Exporting Lactate in High-Lactate Microenvironments. J Biol Chem (2019) 294(52):20135-47. doi: 10.1074/jbc.RA119.009093

74. Halestrap AP. Monocarboxylic Acid Transport. Compr Physiol (2013) 3 (4):1611-43. doi: 10.1002/cphy.c130008

75. Vander Heiden MG, Cantley LC, Thompson CB. Understanding the Warburg Effect: The Metabolic Requirements of Cell Proliferation. Science (2009) 324(5930):1029-33. doi: 10.1126/science.1160809

76. Liu D, Li H. Long non-Coding RNA GEHT1 Promoted the Proliferation of Ovarian Cancer Cells via Modulating the Protein Stability of HIFlalpha. Biosci Rep (2019) 39(5):BSR20181650. doi: 10.1042/BSR20181650

77. Kenny HA, Chiang CY, White EA, Schryver EM, Habis M, Romero IL, et al. Mesothelial Cells Promote Early Ovarian Cancer Metastasis Through Fibronectin Secretion. J Clin Invest (2014) 124(10):4614-28. doi: 10.1172/ JCI7 4778

78. Cheon DJ, Tong Y, Sim MS, Dering J, Berel D, Cui X, et al. A CollagenRemodeling Gene Signature Regulated by TGF-Beta Signaling is Associated
With Metastasis and Poor Survival in Serous Ovarian Cancer. Clin Cancer Res (2014) 20(3):711-23. doi: 10.1158/1078-0432.CCR-13-1256

79. De Donato M, Petrillo M, Martinelli E, Filippetti F, Zannoni GF, Scambia G, et al. Uncovering the Role of Nuclear Lysyl Oxidase (LOX) in Advanced High Grade Serous Ovarian Cancer. Gynecol Oncol (2017) 146(1):170-8. doi: 10.1016/j.ygyno.2017.05.001

80. Ji F, Wang Y, Qiu L, Li S, Zhu J, Liang Z, et al. Hypoxia Inducible Factor lalphaMediated LOX Expression Correlates With Migration and Invasion in Epithelial Ovarian Cancer. Int J Oncol (2013) 42(5):1578-88. doi: 10.3892/ijo.2013.1878

81. Natarajan S, Foreman KM, Soriano MI, Rossen NS, Shehade H, Fregoso DR, et al. Collagen Remodeling in the Hypoxic Tumor-Mesothelial Niche Promotes Ovarian Cancer Metastasis. Cancer Res (2019) 79(9):2271-84. doi: 10.1158/0008-5472.CAN-18-2616

82. Xing Y, Ruan G, Ni H, Qin H, Chen S, Gu X, et al. Tumor Immune Microenvironment and Its Related miRNAs in Tumor Progression. Front Immunol (2021) 12:624725. doi: 10.3389/fimmu.2021.624725

83. Gao Y, Chen L, Cai G, Xiong X, Wu Y, Ma D, et al. Heterogeneity of Immune Microenvironment in Ovarian Cancer and Its Clinical Significance: A Retrospective Study. Oncoimmunology (2020) 9(1):1760067. doi: 10.1080/ 2162402X.2020.1760067

84. Yang L, Wang S, Zhang Q, Pan Y, Lv Y, Chen X, et al. Clinical Significance of the Immune Microenvironment in Ovarian Cancer Patients. Mol Omics (2018) 14(5):341-51. doi: 10.1039/c8mo00128f

85. Zhu X, Shen H, Yin X, Yang M, Wei H, Chen Q, et al. Macrophages Derived Exosomes Deliver miR-223 to Epithelial Ovarian Cancer Cells to Elicit a Chemoresistant Phenotype. J Exp Clin Cancer Res (2019) 38(1):81. doi: 10.1186/s13046-019-1095-1

86. Khan AQ, Rashid K, AlAmodi AA, Raza SS, Uddin S. Recent Developments in Unraveling Signaling Mechanisms Underlying Drug Resistance Due to Cancer Stem-Like Cells. Curr Opin Pharmacol (2020) 54:130-41. doi: 10.1016/j.coph.2020.09.012

87. Rong X, Wei F, Li A, Xiao D, Luo R. Effective Activity of Cytokine Induced Killer Cells Against Hepatocellular Carcinoma Including Tumor-Initiating Cells. Med Hypotheses (2015) 84(3):159-61. doi: 10.1016/j.mehy.2014.08.022

88. Zhou Y, Chen CL, Jiang SW, Feng Y, Yuan L, Chen P, et al. Retrospective Analysis of the Efficacy of Adjuvant CIK Cell Therapy in Epithelial Ovarian Cancer Patients Who Received Postoperative Chemotherapy. Oncoimmunology (2019) 8(2):e1528411. doi: 10.1080/2162402X.2018.1528411

89. Pievani A, Borleri G, Pende D, Moretta L, Rambaldi A, Golay J, et al. DualFunctional Capability of CD3+CD56+ CIK Cells, a T-Cell Subset That Acquires NK Function and Retains TCR-Mediated Specific Cytotoxicity. Blood (2011) 118(12):3301-10. doi: 10.1182/blood-2011-02-336321

90. Mehta BA, Schmidt-Wolf IG, Weissman IL, Negrin RS. Two Pathways of Exocytosis of Cytoplasmic Granule Contents and Target Cell Killing by Cytokine-Induced CD3+ CD56+ Killer Cells. Blood (1995) 86(9):3493-9. doi: 10.1182/blood.V86.9.3493.bloodjournal8693493

91. Zhang Q, Liu XY, Zhang T, Zhang XF, Zhao L, Long F, et al. The DualFunctional Capability of Cytokine-Induced Killer Cells and Application in Tumor Immunology. Hum Immunol (2015) 76(5):385-91. doi: 10.1016/ j.humimm.2014.09.021

92. Bu S, Li B, Wang Q, Gu T, Dong Q, Miao X, et al. Epithelial Ovarian Cancer Stemlike Cells are Resistant to the Cellular Lysis of Cytokineinduced Killer Cells via HIF1Amediated Downregulation of ICAM1. Int J Oncol (2019) 55 (1):179-90. doi: 10.3892/ijo.2019.4794

93. Yang HS, Yoon C, Myung SK, Park SM. Effect of Obesity on Survival of Women With Epithelial Ovarian Cancer: A Systematic Review and MetaAnalysis of Observational Studies. Int J Gynecol Cancer (2011) 21(9):152532. doi: 10.1097/IGC.0b013e31822eb5f8

94. Bae HS, Kim HJ, Hong JH, Lee JK, Lee NW, Song JY. Obesity and Epithelial Ovarian Cancer Survival: A Systematic Review and Meta-Analysis. J Ovarian Res (2014) 7:41. doi: 10.1186/1757-2215-7-41

95. Nieman KM, Kenny HA, Penicka CV, Ladanyi A, Buell-Gutbrod R, Zillhardt MR, et al. Adipocytes Promote Ovarian Cancer Metastasis and Provide Energy for Rapid Tumor Growth. Nat Med (2011) 17(11):1498-503. doi: $10.1038 / \mathrm{nm} .2492$

96. Dai L, Wang C, Song K, Wang W, Di W. Activation of SphK1 by Adipocytes Mediates Epithelial Ovarian Cancer Cell Proliferation. J Ovarian Res (2021) 14(1):62. doi: 10.1186/s13048-021-00815-y 
97. Lengyel E. Ovarian Cancer Development and Metastasis. Am J Pathol (2010) 177(3):1053-64. doi: 10.2353/ajpath.2010.100105

98. Sun C, Li X, Guo E, Li N, Zhou B, Lu H, et al. MCP-1/CCR-2 Axis in Adipocytes and Cancer Cell Respectively Facilitates Ovarian Cancer Peritoneal Metastasis. Oncogene (2020) 39(8):1681-95. doi: 10.1038/ s41388-019-1090-1

99. Ferry G, Tellier E, Try A, Gres S, Naime I, Simon MF, et al. Autotaxin is Released From Adipocytes, Catalyzes Lysophosphatidic Acid Synthesis, and Activates Preadipocyte Proliferation. Up-Regulated Expression With Adipocyte Differentiation and Obesity. J Biol Chem (2003) 278(20):181629. doi: 10.1074/jbc.M301158200

100. Cui R, Bai H, Cao G, Zhang Z. The Role of Lysophosphatidic Acid Receptors in Ovarian Cancer: A Minireview. Crit Rev Eukaryot Gene Expr (2020) 30 (3):265-72. doi: 10.1615/CritRevEukaryotGeneExpr.2020031091

101. Lee J, Park SY, Lee EK, Park CG, Chung HC, Rha SY, et al. Activation of Hypoxia-Inducible Factor-1alpha is Necessary for Lysophosphatidic AcidInduced Vascular Endothelial Growth Factor Expression. Clin Cancer Res (2006) 12(21):6351-8. doi: 10.1158/1078-0432.CCR-06-1252

102. Vogel W, Gish GD, Alves F, Pawson T. The Discoidin Domain Receptor Tyrosine Kinases are Activated by Collagen. Mol Cell (1997) 1(1):13-23. doi: 10.1016/s1097-2765(00)80003-9

103. Jeong BY, Cho KH, Yoon SH, Park CG, Park HW, Lee HY. Discoidin Domain Receptor 2 Mediates Lysophosphatidic Acid-Induced Ovarian Cancer Aggressiveness. Int J Mol Sci (2021) 22(10):5374. doi: 10.3390/ ijms 22105374

104. Grither WR, Divine LM, Meller EH, Wilke DJ, Desai RA, Loza AJ, et al. TWIST1 Induces Expression of Discoidin Domain Receptor 2 to Promote Ovarian Cancer Metastasis. Oncogene (2018) 37(13):1714-29. doi: 10.1038/ s41388-017-0043-9

105. Xu TM, Xin Y, Cui MH, Jiang X, Gu LP. Inhibitory Effect of Ginsenoside Rg3 Combined With Cyclophosphamide on Growth and Angiogenesis of Ovarian Cancer. Chin Med J (Engl) (2007) 120(7):584-8. doi: 10.1097/ 00029330-200704010-00011

106. Liu T, Zhao L, Zhang Y, Chen W, Liu D, Hou H, et al. Ginsenoside 20(S)-Rg3 Targets HIF-1alpha to Block Hypoxia-Induced Epithelial-Mesenchymal Transition in Ovarian Cancer Cells. PloS One (2014) 9(9):e103887. doi: 10.1371/journal.pone.0103887

107. Lu J, Chen H, He F, You Y, Feng Z, Chen W, et al. Ginsenoside 20(S)-Rg3 Upregulates HIF-1alpha-Targeting miR-519a-5p to Inhibit the Warburg Effect in Ovarian Cancer Cells. Clin Exp Pharmacol Physiol (2020) 47 (8):1455-63. doi: 10.1111/1440-1681.13321

108. Bracher F, Tremmel T. From Lead to Drug Utilizing a Mannich Reaction: The Topotecan Story. Arch Pharm (Weinheim) (2017) 350(7):e1600236. doi: $10.1002 /$ ardp.201600236

109. Kummar S, Raffeld M, Juwara L, Horneffer Y, Strassberger A, Allen D, et al. Multihistology, Target-Driven Pilot Trial of Oral Topotecan as an Inhibitor of Hypoxia-Inducible Factor-1alpha in Advanced Solid Tumors. Clin Cancer Res (2011) 17(15):5123-31. doi: 10.1158/1078-0432.CCR-11-0682

110. Rapisarda A, Uranchimeg B, Sordet O, Pommier Y, Shoemaker RH, Melillo G. Topoisomerase I-Mediated Inhibition of Hypoxia-Inducible Factor 1: Mechanism and Therapeutic Implications. Cancer Res (2004) 64(4):1475-82. doi: 10.1158/0008-5472.can-03-3139

111. Rapisarda A, Hollingshead M, Uranchimeg B, Bonomi CA, Borgel SD, Carter $J P$, et al. Increased Antitumor Activity of Bevacizumab in Combination With Hypoxia Inducible Factor-1 Inhibition. Mol Cancer Ther (2009) 8(7):186777. doi: 10.1158/1535-7163.Mct-09-0274

112. Huang WY, Cai YZ, Zhang Y. Natural Phenolic Compounds From Medicinal Herbs and Dietary Plants: Potential Use for Cancer Prevention. Nutr Cancer (2010) 62(1):1-20. doi: 10.1080/01635580903191585

113. He Z, Wu S, Lin J, Booth A, Rankin GO, Martinez I, et al. Polyphenols Extracted From Chinese Hickory (Carya Cathayensis) Promote Apoptosis and Inhibit Proliferation Through the P53-Dependent Intrinsic and HIF1alpha-VEGF Pathways in Ovarian Cancer Cells. Appl Sci (Basel) (2020) 10 (23):8615. doi: 10.3390/app10238615

114. He Z, Chen AY, Rojanasakul Y, Rankin GO, Chen YC. Gallic Acid, a Phenolic Compound, Exerts Anti-Angiogenic Effects via the PTEN/AKT/ HIF-1alpha/VEGF Signaling Pathway in Ovarian Cancer Cells. Oncol Rep (2016) 35(1):291-7. doi: 10.3892/or.2015.4354
115. Hussain I, Waheed S, Ahmad KA, Pirog JE, Syed V. Scutellaria Baicalensis Targets the Hypoxia-Inducible Factor-1alpha and Enhances Cisplatin Efficacy in Ovarian Cancer. J Cell Biochem (2018) 119(9):7515-24. doi: $10.1002 / j \mathrm{cb} .27063$

116. Chen X, Wei L, Yang L, Guo W, Guo Q, Zhou Y. Glycolysis Inhibition and Apoptosis Induction in Human Prostate Cancer Cells by FV-429-Mediated Regulation of AR-AKT-HK2 Signaling Network. Food Chem Toxicol (2020) 143:111517. doi: 10.1016/j.fct.2020.111517

117. Guo Q, Lu L, Liao Y, Wang X, Zhang Y, Liu Y, et al. Influence of C-Src on Hypoxic Resistance to Paclitaxel in Human Ovarian Cancer Cells and Reversal of FV-429. Cell Death Dis (2018) 8(1):e3178. doi: 10.1038/ cddis.2017.367

118. Jia LY, Wu XJ, Gao Y, Rankin GO, Pigliacampi A, Bucur H, et al. Inhibitory Effects of Total Triterpenoid Saponins Isolated From the Seeds of the Tea Plant (Camellia Sinensis) on Human Ovarian Cancer Cells. Molecules (2017) 22(10):1649. doi: 10.3390/molecules22101649

119. Kitagawa I, Hori K, Motozawa T, Murakami T, Yoshikawa M. Structures of New Acylated Oleanene-Type Triterpene Oligoglycosides, Theasaponins E1 and E2, From the Seeds of Tea Plant, Camellia Sinensis (L.) O. Kuntze Chem Pharm Bull (Tokyo) (1998) 46(12):1901-6. doi: 10.1248/cpb.46.1901

120. Adamowicz M, Vermezovic J, d'Adda di Fagagna F. NOTCH1 Inhibits Activation of ATM by Impairing the Formation of an ATM-FOXO3aKAT5/Tip60 Complex. Cell Rep (2016) 16(8):2068-76. doi: 10.1016/ j.celrep.2016.07.038

121. Li B, Tong T, Ren N, Rankin GO, Rojanasakul Y, Tu Y, et al. Theasaponin E1 Inhibits Platinum-Resistant Ovarian Cancer Cells Through Activating Apoptosis and Suppressing Angiogenesis. Molecules (2021) 26(6):1681. doi: $10.3390 /$ molecules 26061681

122. Takai N, Ueda T, Nishida M, Nasu K, Narahara H. Bufalin Induces Growth Inhibition, Cell Cycle Arrest and Apoptosis in Human Endometrial and Ovarian Cancer Cells. Int J Mol Med (2008) 21(5):637-43. doi: 10.3892/ ijmm.21.5.637

123. Zhang JJ, Zhou XH, Zhou Y, Wang YG, Qian BZ, He AN, et al. Bufalin Suppresses the Migration and Invasion of Prostate Cancer Cells Through HOTAIR, the Sponge of miR-520b. Acta Pharmacol Sin (2019) 40(9):122836. doi: 10.1038/s41401-019-0234-8

124. Su S, Dou H, Wang Z, Zhang Q. Bufalin Inhibits Ovarian Carcinoma via Targeting mTOR/HIF-Alpha Pathway. Basic Clin Pharmacol Toxicol (2021) 128(2):224-33. doi: 10.1111/bcpt.13487

125. Ai Z, Lu Y, Qiu S, Fan Z. Overcoming Cisplatin Resistance of Ovarian Cancer Cells by Targeting HIF-1-Regulated Cancer Metabolism. Cancer Lett (2016) 373(1):36-44. doi: 10.1016/j.canlet.2016.01.009

126. Fantin VR, St-Pierre J, Leder P. Attenuation of LDH-A Expression Uncovers a Link Between Glycolysis, Mitochondrial Physiology, and Tumor Maintenance. Cancer Cell (2006) 9(6):425-34. doi: 10.1016/j.ccr.2006.04.023

127. Le A, Cooper CR, Gouw AM, Dinavahi R, Maitra A, Deck LM, et al. Inhibition of Lactate Dehydrogenase A Induces Oxidative Stress and Inhibits Tumor Progression. Proc Natl Acad Sci USA (2010) 107(5):2037-42. doi: 10.1073/pnas.0914433107

128. Garrido MP, Vera C, Vega M, Quest AFG, Romero C. Metformin Prevents Nerve Growth Factor-Dependent Proliferative and Proangiogenic Effects in Epithelial Ovarian Cancer Cells and Endothelial Cells. Ther Adv Med Oncol (2018) 10:1758835918770984. doi: 10.1177/1758835918770984

129. Hart PC, Kenny HA, Grassl N, Watters KM, Litchfield LM, Coscia F, et al. Mesothelial Cell HIF1alpha Expression Is Metabolically Downregulated by Metformin to Prevent Oncogenic Tumor-Stromal Crosstalk. Cell Rep (2019) 29(12):4086-4098 e6. doi: 10.1016/j.celrep.2019.11.079

130. Wen J, Zhao Z, Huang L, Wang L, Miao Y, Wu J. IL-8 Promotes Cell Migration Through Regulating EMT by Activating the Wnt/beta-Catenin Pathway in Ovarian Cancer. J Cell Mol Med (2020) 24(2):1588-98. doi: $10.1111 / j \mathrm{cmm} .14848$

131. Wang Y, Yang J, Gao Y, Du YR, Bao LY, Niu WY, et al. Regulatory Effect of E2, IL-6 and IL-8 on the Growth of Epithelial Ovarian Cancer Cells. Cell Mol Immunol (2005) 2(5):365-72.

132. Yin J, Zeng F, Wu N, Kang K, Yang Z, Yang H. Interleukin-8 Promotes Human Ovarian Cancer Cell Migration by Epithelial-Mesenchymal Transition Induction In Vitro. Clin Transl Oncol (2015) 17(5):365-70. doi: 10.1007/s12094-014-1240-4 
133. Grande F, Aiello F, Garofalo A, Neamati N. Identification and Preclinical Evaluation of SC144, a Novel Pyrroloquinoxaline Derivative With BroadSpectrum Anticancer Activity. Mini Rev Med Chem (2016) 16(8):644-50. doi: $10.2174 / 138955751608160307175649$

134. Lu T, Tang J, Shrestha B, Heath BR, Hong L, Lei YL, et al. Up-Regulation of Hypoxia-Inducible Factor Antisense as a Novel Approach to Treat Ovarian Cancer. Theranostics (2020) 10(15):6959-76. doi: 10.7150/thno.41792

135. Uchida T, Rossignol F, Matthay MA, Mounier R, Couette S, Clottes E, et al. Prolonged Hypoxia Differentially Regulates Hypoxia-Inducible Factor (HIF)-1alpha and HIF-2alpha Expression in Lung Epithelial Cells: Implication of Natural Antisense HIF-1alpha. J Biol Chem (2004) 279 (15):14871-8. doi: 10.1074/jbc.M400461200

136. WeiXing C, Tiantian H, Qun N, Chaohui Y, Ping X. Inhibitory Effect of Hypoxia Inducible Factor-1 Antisense Oligonucleotide on Growth of Human Hepatocellular Carcinoma Cells. Med Oncol (2008) 25(1):88-92. doi: 10.1007/s12032-007-0050-8

137. Zhang W, Liu K, Pei Y, Tan J, Ma J, Zhao J. Long Noncoding RNA HIF1A-AS2 Promotes Non-Small Cell Lung Cancer Progression by the miR-153-5p/S100A14 Axis. Onco Targets Ther (2020) 13:8715-22. doi: 10.2147/OTT.S262293

138. Dai J, Wei R, Zhang P, Kong B. Overexpression of microRNA-195-5p Reduces Cisplatin Resistance and Angiogenesis in Ovarian Cancer by Inhibiting the PSAT1-Dependent GSK3beta/beta-Catenin Signaling Pathway. J Transl Med (2019) 17(1):190. doi: 10.1186/s12967-019-1932-1

139. Yeh YM, Chuang CM, Chao KC, Wang LH. MicroRNA-138 Suppresses Ovarian Cancer Cell Invasion and Metastasis by Targeting SOX4 and HIF1alpha. Int J Cancer (2013) 133(4):867-78. doi: 10.1002/ijc.28086

140. Gu A, Jie Y, Yao Q, Zhang Y, Mingyan E. Slug Is Associated With Tumor Metastasis and Angiogenesis in Ovarian Cancer. Reprod Sci (2017) 24 (2):291-9. doi: 10.1177/1933719116654989

141. Harrison MR, Hahn NM, Pili R, Oh WK, Hammers H, Sweeney C, et al. A Phase II Study of 2-Methoxyestradiol (2ME2) NanoCrystal ${ }^{\circledR}$ Dispersion (NCD) in Patients With Taxane-Refractory, Metastatic Castrate-Resistant Prostate Cancer (CRPC). Investigat N Drugs (2010) 29(6):1465-74. doi: 10.1007/s10637-010-9455-x

142. Matei D, Schilder J, Sutton G, Perkins S, Breen T, Quon C, et al. Activity of 2 Methoxyestradiol (Panzem NCD) in Advanced, Platinum-Resistant Ovarian Cancer and Primary Peritoneal Carcinomatosis: A Hoosier Oncology Group Trial. Gynecol Oncol (2009) 115(1):90-6. doi: 10.1016/j.ygyno.2009.05.042

143. Bruce JY, Eickhoff J, Pili R, Logan T, Carducci M, Arnott J, et al. A Phase II Study of 2-Methoxyestradiol Nanocrystal Colloidal Dispersion Alone and in Combination With Sunitinib Malate in Patients With Metastatic Renal Cell Carcinoma Progressing on Sunitinib Malate. Invest N Drugs (2012) 30 (2):794-802. doi: 10.1007/s10637-010-9618-9

144. Ronnen EA, Kondagunta GV, Ishill N, Sweeney SM, Deluca JK, Schwartz L, et al. A Phase II Trial of 17-(Allylamino)-17-Demethoxygeldanamycin in Patients With Papillary and Clear Cell Renal Cell Carcinoma. Invest $N$ Drugs (2006) 24(6):543-6. doi: 10.1007/s10637-006-9208-z

145. Heath EI, Hillman DW, Vaishampayan U, Sheng S, Sarkar F, Harper F, et al. A Phase II Trial of 17-Allylamino-17-Demethoxygeldanamycin in Patients With Hormone-Refractory Metastatic Prostate Cancer. Clin Cancer Res (2008) 14(23):7940-6. doi: 10.1158/1078-0432.CCR-08-0221

146. Pili R, Liu G, Chintala S, Verheul H, Rehman S, Attwood K, et al. Combination of the Histone Deacetylase Inhibitor Vorinostat With Bevacizumab in Patients With Clear-Cell Renal Cell Carcinoma: A Multicentre, Single-Arm Phase I/II Clinical Trial. Br J Cancer (2017) 116 (7):874-83. doi: 10.1038/bjc.2017.33

147. Haas NB, Quirt I, Hotte S, McWhirter E, Polintan R, Litwin S, et al. Phase II Trial of Vorinostat in Advanced Melanoma. Invest N Drugs (2014) 32 (3):526-34. doi: 10.1007/s10637-014-0066-9

148. Jeong W, Rapisarda A, Park SR, Kinders RJ, Chen A, Melillo G, et al. Pilot Trial of EZN-2968, an Antisense Oligonucleotide Inhibitor of HypoxiaInducible Factor-1 Alpha (HIF-1alpha), in Patients With Refractory Solid Tumors. Cancer Chemother Pharmacol (2014) 73(2):343-8. doi: 10.1007/ s00280-013-2362-z

149. Wu J, Contratto M, Shanbhogue KP, Manji GA, O'Neil BH, Noonan A, et al. Evaluation of a Locked Nucleic Acid Form of Antisense Oligo Targeting HIF-1alpha in Advanced Hepatocellular Carcinoma. World J Clin Oncol (2019) 10(3):149-60. doi: 10.5306/wjco.v10.i3.149
150. Garrett CR, Bekaii-Saab TS, Ryan T, Fisher GA, Clive S, Kavan P, et al. Randomized Phase 2 Study of Pegylated SN-38 (EZN-2208) or Irinotecan Plus Cetuximab in Patients With Advanced Colorectal Cancer. Cancer (2013) 119(24):4223-30. doi: 10.1002/cncr.28358

151. Voss MH, Hussain A, Vogelzang N, Lee JL, Keam B, Rha SY, et al. A Randomized Phase II Trial of CRLX101 in Combination With Bevacizumab Versus Standard of Care in Patients With Advanced Renal Cell Carcinoma. Ann Oncol (2017) 28(11):2754-60. doi: 10.1093/annonc/mdx493

152. Krasner CN, Campos SM, Young CL, Chadda KR, Lee H, Birrer MJ, et al. Sequential Phase II Clinical Trials Evaluating CRLX101 as Monotherapy and in Combination With Bevacizumab in Recurrent Ovarian Cancer. Gynecol Oncol (2021) 162(3):661-6. doi: 10.1016/j.ygyno.2021.07.002

153. Mabjeesh NJ, Escuin D, LaVallee TM, Pribluda VS, Swartz GM, Johnson MS, et al. 2ME2 Inhibits Tumor Growth and Angiogenesis by Disrupting Microtubules and Dysregulating HIF. Cancer Cell (2003) 3(4):363-75. doi: 10.1016/s1535-6108(03)00077-1

154. Liu X, Chen S, Tu J, Cai W, Xu Q. HSP90 Inhibits Apoptosis and Promotes Growth by Regulating HIF-1alpha Abundance in Hepatocellular Carcinoma. Int J Mol Med (2016) 37(3):825-35. doi: 10.3892/ijmm.2016.2482

155. Neckers L, Neckers K. Heat-Shock Protein 90 Inhibitors as Novel Cancer Chemotherapeutic Agents. Expert Opin Emerg Drugs (2002) 7(2):277-88. doi: 10.1517/14728214.7.2.277

156. Rocha S, Hutt DM, Roth DM, Vignaud H, Cullin C, Bouchecareilh M. The Histone Deacetylase Inhibitor, Vorinostat, Represses Hypoxia Inducible Factor 1 Alpha Expression Through Translational Inhibition. PloS One (2014) 9(8):e106224. doi: 10.1371/journal.pone.0106224

157. Greenberger LM, Horak ID, Filpula D, Sapra P, Westergaard M, Frydenlund HF, et al. A RNA Antagonist of Hypoxia-Inducible Factor-1alpha, EZN2968, Inhibits Tumor Cell Growth. Mol Cancer Ther (2008) 7(11):3598-608. doi: 10.1158/1535-7163.MCT-08-0510

158. Sapra P, Zhao H, Mehlig M, Malaby J, Kraft P, Longley C, et al. Novel Delivery of SN38 Markedly Inhibits Tumor Growth in Xenografts, Including a Camptothecin-11-Refractory Model. Clin Cancer Res (2008) 14(6):188896. doi: 10.1158/1078-0432.CCR-07-4456

159. Sapra P, Kraft P, Pastorino F, Ribatti D, Dumble M, Mehlig M, et al. Potent and Sustained Inhibition of HIF-1alpha and Downstream Genes by a Polyethyleneglycol-SN38 Conjugate, EZN-2208, Results in Anti-Angiogenic Effects. Angiogenesis (2011) 14(3):245-53. doi: 10.1007/s10456-011-9209-1

160. Pham E, Birrer MJ, Eliasof S, Garmey EG, Lazarus D, Lee CR, et al. Translational Impact of Nanoparticle-Drug Conjugate CRLX101 With or Without Bevacizumab in Advanced Ovarian Cancer. Clin Cancer Res (2015) 21(4):808-18. doi: 10.1158/1078-0432.CCR-14-2810

161. Zhong H, De Marzo AM, Laughner E, Lim M, Hilton DA, Zagzag D, et al. Overexpression of Hypoxia-Inducible Factor lalpha in Common Human Cancers and Their Metastases. Cancer Res (1999) 59(22):5830-5.

162. Pontén F, Jirström K, Uhlen M. The Human Protein Atlas-a Tool for Pathology. J Pathol (2008) 216(4):387-93. doi: 10.1002/path.2440

163. Pujade-Lauraine E, Hilpert F, Weber B, Reuss A, Poveda A, Kristensen G, et al. Bevacizumab Combined With Chemotherapy for Platinum-Resistant Recurrent Ovarian Cancer: The AURELIA Open-Label Randomized Phase III Trial. J Clin Oncol (2014) 32(13):1302-8. doi: 10.1200/JCO.2013.51.4489

164. Miller K, Wang ML, Gralow J, Dickler M, Cobleigh M, Perez EA, et al. Paclitaxel Plus Bevacizumab Versus Paclitaxel Alone for Metastatic Breast Cancer. N Engl J Med (2007) 357(26):2666-76. doi: 10.1056/NEJMoa072113

165. Vaupel P. Tumor Microenvironmental Physiology and Its Implications for Radiation Oncology. Semin Radiat Oncol (2004) 14(3):198-206. doi: 10.1016/j.semradonc.2004.04.008

166. Basavarajappa L, Rijal G, Hoyt K. Multifocused Ultrasound Therapy for Controlled Microvascular Permeabilization and Improved Drug Delivery. IEEE Trans Ultrason Ferroelectr Freq Control (2021) 68(4):961-8. doi: 10.1109/TUFFC.2020.3026697

Conflict of Interest: The authors declare that the research was conducted in the absence of any commercial or financial relationships that could be construed as a potential conflict of interest.

Publisher's Note: All claims expressed in this article are solely those of the authors and do not necessarily represent those of their affiliated organizations, or those of the publisher, the editors and the reviewers. Any product that may be evaluated in 
this article, or claim that may be made by its manufacturer, is not guaranteed or endorsed by the publisher.

Copyright $\odot 2021$ Wang, Du, Xu, Wang, Li, Gao, Li and Zhu. This is an open-access article distributed under the terms of the Creative Commons Attribution
License (CC BY). The use, distribution or reproduction in other forums is permitted, provided the original author(s) and the copyright owner(s) are credited and that the original publication in this journal is cited, in accordance with accepted academic practice. No use, distribution or reproduction is permitted which does not comply with these terms. 